\title{
Cellulose propionate/poly(N-vinyl pyrrolidone-co-vinyl acetate) blends: dependence of the miscibility on propionyl DS and copolymer composition
}

\section{$\operatorname{AUTHOR}(\mathrm{S}):$}

Sugimura, Kazuki; Katano, Shougo; Teramoto, Yoshikuni; Nishio, Yoshiyuki

\section{CITATION:}

Sugimura, Kazuki ...[et al]. Cellulose propionate/poly(N-vinyl pyrrolidone-co-vinyl acetate) blends: dependence of the miscibility on propionyl DS and copolymer composition. Cellulose 2013, 20(1): 239-252

\section{ISSUE DATE:}

2013-02

URL:

http://hdl.handle.net/2433/169674

\section{RIGHT:}

The final publication is available at www.springerlink.com; This is not the published version. Please cite only the published version.; この論文 は出版社版でありません。引用の際には出版社版をご確認ご利用くだ さい。 
1 Cellulose propionate/poly( $N$-vinyl pyrrolidone-co-vinyl acetate) blends: dependence of

2 the miscibility on propionyl DS and copolymer composition

3

4 Kazuki Sugimura, Shougo Katano, Yoshikuni Teramoto, and Yoshiyuki Nishio*

5

6 Division of Forest and Biomaterials Science, Graduate School of Agriculture, Kyoto

7 University, Sakyo-ku, Kyoto 606-8502, Japan

8

$9 \quad *$ To whom correspondence should be addressed.

10 E-mail: ynishio@kais.kyoto-u.ac.jp. Tel.: +81 $757536250 . \quad$ Fax: +81 757536300. 
Abstract: Blend miscibility of cellulose propionate (CP) with synthetic copolymers comprising $N$-vinyl pyrrolidone (VP) and vinyl acetate (VAc) units was examined, and a data map was constructed as a function of the degree of substitution (DS) of CP and the VP fraction in the copolymer component. Results of DSC and FT-IR measurements indicated that the pairing of $\mathrm{CP} / \mathrm{P}(\mathrm{VP}-\mathrm{co}-\mathrm{VAc})$ formed a miscible or immiscible blend system according to the balance in effectiveness of the following factors: 1) hydrogen bonding between residual hydroxyls of $\mathrm{CP}$ and VP carbonyls of $\mathrm{P}(\mathrm{VP}-\mathrm{co}-\mathrm{VAc})$; 2) steric hindrance of propionyl side-groups to the interaction specified in 1); 3) intramolecular repulsion between the two units constituting the vinyl copolymer; and, additionally, 4) structural affinity between two segmental moieties involving the propionyl group and VAc unit, respectively. The factor 3 inducing intercomponent attraction is responsible for the appearance of a so-called "miscibility window" in the miscibility map, and the factor 4 substantially expands the miscible region whole, wider relative to those in the maps for the corresponding blend series based on cellulose acetate and butyrate. In further refined estimation by DMA and $T_{1 \rho}{ }^{\mathrm{H}}$ quantification in solid-state ${ }^{13} \mathrm{C} \mathrm{NMR}$, it was found that the miscible blends of hydrogen-bonding type (using CPs of DS < 2.7) were completely homogeneous on a scale within a few nanometers, whereas the polymer pairs situated in the window region (using CPs of DS > 2.7) formed blends exhibiting a somewhat larger size of heterogeneity (ca. 5-20 nm).

Keywords: Blends; Cellulose propionate; Poly( $N$-vinyl pyrrolidone-co-vinyl acetate); Miscibility; Scale of homogeneity 


\section{Introduction}

As is well known, polymer blending is useful to improve the original physical properties of one or both of the components, and also to obtain new polymeric materials exhibiting wide-ranging properties and/or synergistic functions unattainable in single-component materials (Ultracki 1990). This should also be applicable to the blending of cellulosics as one component (Nishio 1994). Especially cellulose esters (CEs) are versatile cellulosic derivatives and essential for further applications in various fields including molded plastics, fibers, optical films, membranes, coatings, etc., and, therefore, a number of fundamental and practical blend studies of CEs have been carried out (Edgar et al. 2001; Nishio 2006).

In previous papers (Miyashita et al. 2002; Ohno et al. 2005; Ohno and Nishio 2006), the authors' group has investigated the miscibility and intermolecular interactions for blends of industrially crucial CEs, cellulose acetate (CA) and butyrate (CB), with synthetic homo- and copolymers comprising $N$-vinyl pyrrolidone (VP) and/or vinyl acetate (VAc) units, i.e., $\operatorname{poly}(N$-vinyl pyrrolidone) (PVP), poly(vinyl acetate) (PVAc), $\operatorname{poly}(N$-vinyl pyrrolidone-co-vinyl acetate) (P(VP-co-VAc)). Through thermal analysis by differential scanning calorimetry (DSC), it was shown that the miscibility behaviour of the CA or $\mathrm{CB} /$ vinyl polymer pairs (generically described as $\mathrm{CE} / \mathrm{P}(\mathrm{VP}-\mathrm{co}-\mathrm{VAc})$ ) was seriously affected by the degree of substitution (DS) and the ester side-chain length of the CE component, as well as by the VP fraction in the copolymer component. Two maps given in Figure 1 survey the estimation result.

\section{$<<$ Figure 1 (a) \& (b) $>>$}

In the CA/P(VP-co-VAc) system (Fig. 1a), Fourier transform infrared (FT-IR) and solid-state ${ }^{13} \mathrm{C}$ CP/MAS NMR spectroscopy revealed that the blend miscibility was mainly governed by the hydrogen-bonding interactions between the residual hydroxyls of CA and the carbonyls of VP units in $\mathrm{P}(\mathrm{VP}-\mathrm{co}$-VAc) and the miscible blends of this interaction type were 
homogeneous in a few nanometers scale (Miyashita et al. 2002; Ohno et al. 2005). In the $\mathrm{CB} / \mathrm{P}(\mathrm{VP}-\mathrm{co}-\mathrm{VAc}$ ) system (Fig. 1b), the hydrogen-bonding interaction was suppressed in frequency by steric hindrance of the bulky butyryl substituent, resulting in lowering of the critical DS required for attainment of the miscibility of CE with PVP and VP-rich copolymers (VP content $>65 \mathrm{~mol} \%$ ), as the critical values of 2.5 for $\mathrm{CB}$ and 2.8 for $\mathrm{CA}$ are designated in Figure 1. Furthermore, unlike the situation for the CA blends, highly substituted CBs of DS $=2.5-2.95$ made a miscible pair with $\mathrm{P}(\mathrm{VP}-\mathrm{co}$-VAc) copolymers containing ca. $30-65 \mathrm{~mol} \%$ VP residues (Ohno and Nishio 2006). This unique copolymer composition range, generally termed a 'miscibility window', emerges as a result of indirect polymer-copolymer attraction driven by strong repulsion between the VP and VAc constituents of the random copolymer. More concretely, since these two monomer species having mutually repellent characters were randomly combined in $\mathrm{P}(\mathrm{VP}-\mathrm{co}$-VAc) by covalent bonding, the copolymers tended to form a miscible monophase with $\mathrm{CB}$ ( $\mathrm{DS}>2.5$ ) so as to reduce the strong repulsion between the comonomers (Ohno and Nishio 2007). The absence of such a clear miscibility window in the map for the CA/P(VP-co-VAc) system may be interpreted as due to a strong self-association ability of highly substituted CAs of DS > 2.8; the CAs rather crystallize in a cellulose triacetate II form.

As an extension of the above studies, our attention was then directed to a similar miscibility map for cellulose propionate (CP)/P(VP-co-VAc) blends; the side-chain length of the CE component is just intermediate between the acetyl and butyryl substituents. Great interests are how far the miscible region spreads on the map constructed as a function of the DS and copolymer composition, and whether that kind of miscibility window emerges or not. Thereby, we will be able to make clearer the effects of the ester side-group and residual hydroxyls of CE on the blend miscibility and intermolecular interactions with the vinyl polymers concerned. In addition to conventional characterizations by DSC analysis and IR and NMR spectra, the homogeneity of miscible blends is evaluated in refinements of the 
mixing scale by complementary use of dynamic mechanical analysis (DMA) and proton spin-lattice relaxation time $\left(T_{1 \rho}{ }^{\mathrm{H}}\right)$ measurements in solid-state ${ }^{13} \mathrm{C}$ NMR spectroscopy.

\section{Experimental}

Materials

Cellulose propionate $(\mathrm{CP})$ samples were synthesized from cotton cellulose with a viscosity average molecular weight of 252,000 via a homogeneous reaction with acid chloride/base catalyst, in a procedure similar to that used in previous studies (Kusumi et al. 2008; Nishio et al. 1997). Table 1 summarizes the characterization data including DS, molecular weight, and glass transition temperature $\left(T_{\mathrm{g}}\right)$ for all the $\mathrm{CP}$ samples used in this study. The vinyl polymers employed as a mixing partner for the CPs were poly $(N$-vinyl pyrrolidone) (PVP), poly(vinyl acetate) (PVAc), and poly( $N$-vinyl pyrrolidone-co-vinyl acetate) (P(VP-co-VAc)), basically the same as those in the preceding papers (Miyashita et al. 2002; Ohno and Nishio 2006). Data of characterization for all the vinyl polymers are also listed in Table 1. As shown in the table, any of the $\mathrm{P}(\mathrm{VP}-\mathrm{co}-\mathrm{VAc})$ samples exhibited a single $T_{\mathrm{g}}$, and the $T_{\mathrm{g}}$ versus copolymer composition relation was in good obedience to the Fox equation (Fox and Flory 1954). Thus the copolymers were all regarded as essentially random copolymer. Hereafter, a $\mathrm{CP}$ sample with $\mathrm{DS}=x$ is encoded as $\mathrm{CP}_{x}$, and a code $\mathrm{P}\left(\mathrm{VP}_{y}-\right.$ co- $\left.\mathrm{VAc}_{z}\right)$ denotes $\mathrm{P}(\mathrm{VP}-\mathrm{co}$-VAc $)$ copolymer of VP:VAc $=y: z$ (in molar ratio).

\section{$<<$ Table 1 $>>$}

Preparation of blend samples

$\mathrm{CP} /$ vinyl polymer blends were prepared in film form from mixed polymer solutions by 
111 solvent evaporation, in the same manner as that adopted in the preceding works (Miyashita et al. 2002; Ohno and Nishio 2006). N,N-Dimethylformamide was selected as a common solvent and the film casting was carried out at $50{ }^{\circ} \mathrm{C}$ under reduced pressure $(<10 \mathrm{mmHg})$.

The as-cast samples thus obtained were further dried at $50{ }^{\circ} \mathrm{C}$ in vacuo for 3 days.

For DMA measurements, the solution-cast samples were thermally molded into a flattened film ca. $0.1 \mathrm{~mm}$ thick by using a Toyo-Seiki hot-pressing apparatus. The hot-press molding was conducted at $230{ }^{\circ} \mathrm{C}$ with an applied pressure of $15 \mathrm{MPa}$ for $30 \mathrm{~s}$.

\section{Measurements}

DSC thermal analysis was carried out with a Seiko DSC 6200/EXSTAR 6000 apparatus. The temperature readings were calibrated with an indium standard. The calorimetry measurements were conducted on ca. 5-mg samples packed in an aluminum pan under a nitrogen atmosphere. Each sample was first heated from ambient temperature $\left(\sim 25^{\circ} \mathrm{C}\right)$ to $230{ }^{\circ} \mathrm{C}$ at a scanning rate of $20{ }^{\circ} \mathrm{C} / \mathrm{min}$, and then immediately quenched to $-50{ }^{\circ} \mathrm{C}$ at a rate of $80{ }^{\circ} \mathrm{C} / \mathrm{min}$. Following this, the second heating scan was run from $-50{ }^{\circ} \mathrm{C}$ to $230{ }^{\circ} \mathrm{C}$ at a rate of $20{ }^{\circ} \mathrm{C} / \mathrm{min}$ to record stable thermograms. Thermograms presented in this paper were all obtained in the second heating scan and the $T_{\mathrm{g}}$ was taken as a temperature at the midpoint of a baseline shift in heat flow characterizing the glass transition.

FT-IR spectra were measured on thinner film samples $(<20 \mu \mathrm{m}$ thick $)$ by using a Shimazu IRPrestige-21 spectrometer. All the spectra were recorded at $20{ }^{\circ} \mathrm{C}$ in a transmission method over a wavenumber range $400-4000 \mathrm{~cm}^{-1}$ with a resolution of $2 \mathrm{~cm}^{-1}$ via accumulation of 64 scans.

DMA was conducted by using a Seiko DMS6100/EXSTAR6000 apparatus. Strips of rectangular shape $\left(20 \times 5 \mathrm{~mm}^{2}\right)$ cut from the molded films were used for measurements of the temperature dependence of the dynamic storage modulus $\left(E^{\prime}\right)$ and loss modulus $\left(E^{\prime \prime}\right)$. The 
137 measuring conditions were as follows: temperature range, $-150-300{ }^{\circ} \mathrm{C}$; scanning rate, $2{ }^{\circ} \mathrm{C} / \mathrm{min}$; oscillatory frequency, $10 \mathrm{~Hz}$.

High-resolution solid-state NMR experiments were performed at $20{ }^{\circ} \mathrm{C}$ in a Varian NMR system $400 \mathrm{MHz}$ operated at a ${ }^{13} \mathrm{C}$ frequency of $100.6 \mathrm{MHz}$. The magic-angle spinning rate was $15.0 \mathrm{kHz} .{ }^{13} \mathrm{C} \mathrm{CP} / \mathrm{MAS}$ spectra were measured with a contact time of $2 \mathrm{~ms}$, and a $90^{\circ}$ pulse width of $2.9 \mu$ s was employed. In the measurements of $T_{1 \rho}{ }^{\mathrm{H}}$, a contact time of $0.2 \mathrm{~ms}$ was used, and a proton spin-locking time $\tau$ ranged from 0.5 to $30 \mathrm{~ms}$. 2048 scans were done to obtain the ${ }^{13} \mathrm{C} \mathrm{CP} / \mathrm{MAS}$ spectra, while 4096 scans were accumulated for the relaxation time measurements. Chemical shifts of ${ }^{13} \mathrm{C}$ spectra represented in ppm were referred to tetramethylsilane by using the methine carbon resonance $(29.47 \mathrm{ppm})$ of admantane crystals as an external reference standard. In order to minimize any possible effect due to the thermal history and/or residual solvents, each sample was heat-treated at $250{ }^{\circ} \mathrm{C}$ in vacuo for 5 min just before the measurement.

\section{Results and discussion}

Estimation of miscibility and intermolecular interaction

The miscibility state in the present $\mathrm{CP} /$ vinyl polymer system was estimated basically by $T_{\mathrm{g}}$ determination in DSC; generally, if any blend sample of a given polymer/polymer pair exhibits a single glass transition between the $T_{\mathrm{g}} \mathrm{s}$ of the two component polymers and a composition-dependent shift of the blend $T_{\mathrm{g}}$ is clearly observed, then the pair can be regarded as a miscible one on the $T_{\mathrm{g}}$-detection scale that is usually assumed to be less than a couple of tens of nanometers (Kaplan 1976; Nishio 1994; Ultracki 1990). To examine the presence of intermolecular interactions, different blend compositions of selected CP/vinyl polymer pairs were subjected to FT-IR and CP/MAS NMR spectra measurements. 


\section{CP/PVP blends}

165

166

When CPs of DS $=1.71-2.62$ were used as a counter component to PVP, the solution-cast blend films prepared at 10/90-90/10 (wt/wt) compositions were all transparent in the visual inspection. By contrast, CP/PVP blends of propionyl DS $=2.72-2.93$ formed a comparatively cloudy film at intermediate compositions of $40-70 \mathrm{wt} \% \mathrm{CP}$ content.

Figure 2a displays DSC thermograms obtained for $\mathrm{CP}_{2.72} / \mathrm{PVP}$ blends. From reading of the midpoint of the respective discontinuities in heat flow, $T_{\mathrm{g}}$ of $\mathrm{CP}_{2.72}$ and that of PVP were evaluated as $134{ }^{\circ} \mathrm{C}$ and $177{ }^{\circ} \mathrm{C}$, respectively. For the blend samples of 20/80-80/20 compositions, two independent glass transitions originating from the two components were clearly detected at almost the same positions as those observed for the unblended samples. This behaviour of double $T_{\mathrm{g}} \mathrm{s}$ was also noted for $\mathrm{CP}_{2.81} / \mathrm{PVP}$ and $\mathrm{CP}_{2.93} / \mathrm{PVP}$ blends. Thus, the CPs of DS > 2.7 are taken as immiscible with PVP.

\section{$<<$ Figure 2 (a) \& (b) >>}

Contrastively, the other six pairs of CP/PVP using propionyl DSs of $<2.7$ imparted a miscible sign. Figure $2 \mathrm{~b}$ exemplifies DSC thermograms of $\mathrm{CP}_{2.62} / \mathrm{PVP}$ blends. $\quad T_{\mathrm{g}}$ of $\mathrm{CP}_{2.62}$ was determined to be $138{ }^{\circ} \mathrm{C}$. The blends with PVP gave a single, composition-dependent $T_{\mathrm{g}}$ that shifted to higher temperatures along with an increase in the PVP content; thus we can conclude that the CP forms a miscible monophase with PVP. This was also the case for the other CPs of DS $=1.71-2.54$.

Figure 3 compiles FT-IR spectra obtained for blends of the miscible $\mathrm{CP}_{1.71} / \mathrm{PVP}$ pair, on an enlarged scale for two regions of (a) $\mathrm{O}-\mathrm{H}$ and (b) $\mathrm{C}=\mathrm{O}$ stretching vibrations. As shown in Figure 3a, the unblended CP (top data) gave a band centering at $3,482 \mathrm{~cm}^{-1}$, which can be associated with a mixture of free hydroxyls and intramolecularly hydrogen-bonded $\mathrm{OH}$ groups. For the blends, it was observed that the band peak shifted to lower wavenumber positions with increasing PVP content, and, concomitantly, another absorption signal became 
more discernible as a shoulder on the side of further lower wavenumbers, as marked by a white arrow at $\sim 3,300 \mathrm{~cm}^{-1}$ in Figure 3a. This new band can be ascribed to the stretching of intermolecularly hydrogen-bonded $\mathrm{OH}$ groups (Marchessault and Liang 1960).

$$
<<\text { Figure } 3 \text { (a) \& (b) >> }
$$

Concerning the region of $\mathrm{C}=\mathrm{O}$ stretching vibration (Fig. $3 \mathrm{~b}$ ), a $1,744 \mathrm{~cm}^{-1}$ band involved in the propionyl side-group of the $\mathrm{CP}$ component was almost unchanged in the peak location by the blending with PVP. However, a carbonyl signal of PVP, observed at $1,675 \mathrm{~cm}^{-1}$ for the homopolymer, became asymmetric progressively as the CP content increased in the binary mixture; consequently, the absorption band was dividable into two peaks, a larger one at $\sim 1,680 \mathrm{~cm}^{-1}$ and a smaller one at $\sim 1,660 \mathrm{~cm}^{-1}$ (see data for CP-rich compositions in Fig. $3 b$ ). These two split IR signals for the PVP component may be associated with the free carbonyl and hydrogen-bonded carbonyl groups, respectively (Masson and Manley 1991).

The above observations of the frequency shift and shape variation for the specific IR bands are evidently attributed to the hydrogen-bonding interaction between the residual hydroxyls of the CP component and the carbonyls of the PVP component. Conversely, this attractive interaction would contribute as a driving force to develop the good miscibility of the CP/PVP blends, as did in the CA/PVP (Miyashita et al. 2002; Ohno et al. 2005) and CB/PVP systems (Ohno and Nishio 2006). In a corroborating experiment, the immiscible CP/PVP blends using highly substituted CPs of DS $=2.81$ and 2.93 exhibited no systematic variation of the corresponding bands in their FT-IR spectra.

By comprehensive comparison with the previous estimation shown in Figure 1, we notice that the upper limit in DS of CP miscible with PVP, which is $\sim 2.7$, is just intermediate between the corresponding ones, 2.8 and 2.5 , for $\mathrm{CA}$ and $\mathrm{CB}$, respectively. This is readily interpretable as due to the difference in effectiveness of the steric hindrance between the three ester side-groups which can inhibit the hydrogen-bonding interaction stated above, in consideration of the order of bulkiness for the acetyl, propionyl, and butyryl substituents. 


\section{CP/PVAc blends}

As-cast films of CP/PVAc blends were mostly transparent to the naked eye (i.e., optically compatible) over the whole composition range. However, taking account of the refractive index 1.47-1.49 of CP, close to that of PVAc (1.4665 (Seferis 1999)), we should note that the transparency of these films is not directly linked to the blend miscibility.

Figure 4 collects $T_{\mathrm{g}}$ versus composition plots for eight series of CP/PVAc blends (propionyl DS $=1.90-2.93$ ). As can be seen from the plots, the three blend series using CPs of DS $=1.90,2.18$, and 2.35 were completely immiscible, because two $T_{\mathrm{g}}$ signals appeared without any noticeable shift from their original locations for the two components. Regarding the other blend series using CPs of DS $>2.5$, however, an appreciable extent of $T_{\mathrm{g}}$ shift was detected for both of the two components at compositions of CP/PVAc $=60 / 40-90 / 10$, indicating that a certain amount of the CP constituent was dissolved into the PVAc phase, and vice versa. Therefore, we judge the $\mathrm{CP}(\mathrm{DS}>2.5) / \mathrm{PVAc}$ pairs to be partially miscible. Such partial miscibility was never definable to the CA/PVAc and CB/PVAc systems irrespective of DS of the CA or CB component; any blend of both systems provided two invariable $T_{\mathrm{g}} \mathrm{s}$ independent of the mixing composition.

\section{$<<$ Figure 4 $>>$}

The finding of the partial miscibility (or better compatibility) for the pairs of highly propionylated $\mathrm{CP} / \mathrm{PVAc}$ is quite significant in the present study, as embodied below for $\mathrm{CP}$ blends with the copolymer $\mathrm{P}(\mathrm{VP}-\mathrm{co}-\mathrm{VAc})$. A structural affinity between the propionyl side-group ( $\left.\underline{\mathrm{CH}_{3}}-\underline{\mathrm{C}} \mathrm{H}_{2}-\underline{\mathrm{CO}}-\underline{\mathrm{O}}-\underline{\mathrm{C}}-\right)$ and the VAc unit $\left(-\left(\underline{\mathrm{C}} \mathrm{H}_{2}-\underline{\mathrm{C}} \mathrm{H}\left(-\underline{\mathrm{O}}-\underline{\mathrm{CO}}-\underline{\mathrm{C}} \mathrm{H}_{3}\right)\right)-\right)$ might be responsible to the advent of the partial miscibility, as we have pointed out a similar effect in former studies on CE/poly( $\varepsilon$-caprolactone) blends (Nishio et al. 1997; Kusumi et al. 2008). The two structural unities containing a carbonyl moiety may be favorable for a relatively weak interaction of dipole-dipole antiparallel alignment. The presence of such a weak 
interaction is also suggested in earlier papers dealing with a miscible system of PVAc with

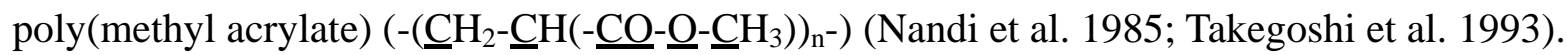

\section{$C P / P(V P-c o-V A c)$ blends}

In visual appearance, as-cast films of CP blends with VP-VAc copolymers were homogeneous and transparent, except for films of several polymer pairs composed of CP of DS > 2.7 and $\mathrm{P}(\mathrm{VP}-\mathrm{co}$-VAc) having more than $70 \mathrm{~mol} \% \mathrm{VP}$ residues.

Figure 5 displays $T_{\mathrm{g}}$ variations with mixing composition for eight series of $\mathrm{CP}_{1.90} / \mathrm{P}(\mathrm{VP}-\mathrm{co}-\mathrm{VAc})$ blends, the VP fraction of the copolymer component ranging from 10 to $87 \mathrm{~mol} \%$. In the data plotting, when the VP fraction in P(VP-co-VAc) was $\geq 23 \mathrm{~mol} \%$, any blend series of $\mathrm{CP}_{1.90} / \mathrm{P}(\mathrm{VP}-\mathrm{co}-\mathrm{VAc})$ provided a smooth variation of a single $T_{\mathrm{g}}$ situated between the $T_{\mathrm{g}}$ values of the two unblended components. Thus, it turns out that $\mathrm{CP}_{1.90}$ forms a miscible monophase with $\mathrm{P}(\mathrm{VP}-\mathrm{co}-\mathrm{VAc}) \mathrm{s}$ of $\mathrm{VP}>\sim 20 \mathrm{~mol} \%$. For selected blends of the miscible pairs, the presence of the hydrogen-bonding interaction between the CP-hydroxyl and VP-carbonyl groups was also ascertained by FT-IR measurements. With regard to a

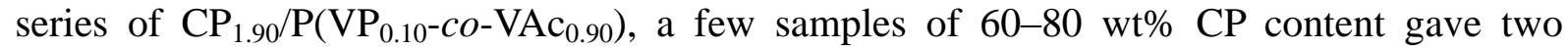
discrete $T_{\mathrm{g}} \mathrm{S}$, yet there occurred a noticeable extent of $T_{\mathrm{g}}$ shift over all the blend compositions, as can be seen from Figure 5. Therefore, exceptionally, this polymer pair is evaluated to be partially miscible.

$\mathrm{CP}$ was partially miscible with $\mathrm{P}\left(\mathrm{VP}_{0.10}-\mathrm{co}-\mathrm{VAc}_{0.90}\right)$ and completely miscible with the other copolymers of VP:VAc $=23: 77-87: 13$. Intriguingly, $\mathrm{CP}_{2.35}, \mathrm{CP}_{2.54}$, and $\mathrm{CP}_{2.62}$ were all completely miscible even with $\mathrm{P}\left(\mathrm{VP}_{0.10}-c o-\mathrm{VAc}_{0.90}\right)$ as well as with the others of $\mathrm{VP}>20$ mol\%.

In the same way, $\mathrm{CP}_{2.18}$ showed a similar miscibility behaviour to that of $\mathrm{CP}_{1.90}$; viz., the When the propionyl DS of the CP component reached 2.72 and more, the CPs were 
miscible with $\mathrm{P}(\mathrm{VP}-\mathrm{co}-\mathrm{VAc}) \mathrm{s}$ of ca. $10-65 \mathrm{~mol} \% \mathrm{VP}$ residues, despite their imperfect miscibility with PVAc and PVP homopolymers. Figure 6 exemplifies the miscible evidence

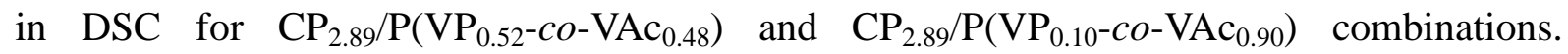
Accordingly, it follows that the $\mathrm{CP} / \mathrm{P}(\mathrm{VP}-\mathrm{co}$-VAc) system exhibited a definite miscibility window, as did the previous $\mathrm{CB} / \mathrm{P}(\mathrm{VP}-\mathrm{co}-\mathrm{VAc})$ system (see Fig. 1b). As for the miscibility window of the latter system, it was reasonably concluded that a greater repulsion between the VP and VAc units in the random copolymer was mainly contributory to the miscibility attainment; this was rationalized by assessment of the Krigbaum-Wall interaction parameters (Ohno and Nishio 2007). The intramolecular copolymer effect may also be applicable to the present $\mathrm{CP}(\mathrm{DS}>2.7) / \mathrm{P}(\mathrm{VP}-\mathrm{co}-\mathrm{VAc})$ blends.

\section{$<<$ Figure 6 (a) \& (b) $>>$}

It should be stressed here that the CPs of DS $>2.7$ were miscible with $\mathrm{P}\left(\mathrm{VP}_{0.10}\right.$-co- $\left.\mathrm{VAc}_{0.90}\right)$ abundant in VAc residues, as was the case for the ones of $\mathrm{DS}=$ 2.35-2.62. At the comonomer ratio of $\mathrm{VP}: \mathrm{VAc}=10: 90$, the intramolecular repulsion effect would decline to a considerable extent; instead, however, the interaction coming from the structural affinity between the ester side-group of $\mathrm{CP}$ and the VAc unit of the copolymer would be more prevailing. It can therefore be assumed that, as a result of favorable balance of the two effects, the high-substituted CPs were miscible with $\mathrm{P}\left(\mathrm{VP}_{0.10}-c o-\mathrm{VAc}_{0.90}\right)$. To find a spectroscopic evidence of the latter interaction in which both CP- and VAc-carbonyls should be involved, we carried out FT-IR and solid-state ${ }^{13} \mathrm{C}$ CP/MAS NMR measurements for $\mathrm{CP}_{2.89} / \mathrm{P}\left(\mathrm{VP}_{0.10}-c o-\mathrm{VAc}_{0.90}\right)$ and $\mathrm{CP}_{2.89} / \mathrm{P}_{\left(\mathrm{VP}_{0.52}-c o-\mathrm{VAc}_{0.48}\right)}$ blends. In the IR examination, however, the $\mathrm{C}=\mathrm{O}$ stretching band of $\mathrm{CP}$ overlapped completely with the one of VAc. In the CP-MAS spectra measurements, the unblended copolymers gave a carbonyl resonance signal composed of two splitting peaks with their maximum at $171 \mathrm{ppm}$ (for VAc unit) and $175 \mathrm{ppm}$ (for VP unit); the splitting was relatively clear in a data for $\mathrm{P}\left(\mathrm{VP}_{0.52}-\mathrm{co}-\mathrm{VAc}_{0.48}\right)$ (see Fig. 9). Nevertheless, when the carbonyl carbon resonance of CP (173.5 ppm) merged with the split 
293

294

295

296

297

298

299

300

301

signal of the VP/VAc units, it was difficult to precisely estimate the respective three chemical shifts. Thus the structural affinity effect was undetectable for any of the blends; it appears to be substantially feeble, however.

On the basis of the thermal analysis data, we successfully constructed a miscibility map for the CP/P(VP-co-VAc) system, as shown in Figure 7. The diagram indicates that CPs of DS $<2.7$, having a relatively higher amount of residual $\mathrm{OH}$ groups, are mostly miscible with the vinyl polymers of $\mathrm{VP}>\sim 20 \mathrm{~mol} \%$, primarily due to predominance of the hydrogen-bonding interaction. A miscibility window emerges in the region satisfying propionyl DS > 2.7 and VP fraction $=10-65 \mathrm{~mol} \%$, as a result of indirect intercompoent attraction due to the stronger repulsion effect in the $\mathrm{P}(\mathrm{VP}-\mathrm{co}-\mathrm{VAc})$ component itself. To make a comparison of the map with the previous ones (Fig. 1) for the corresponding blend systems of $\mathrm{CA}$ and $\mathrm{CB}$, we find that the $\mathrm{CP}$ system produced the largest miscible region. As compared with the map for the CB blends, the DS boundary partitioning the miscibility states of $\mathrm{CP} / \mathrm{P}(\mathrm{VP}-\mathrm{co}$-VAc) ( $\mathrm{VP} \geq 65 \mathrm{~mol} \%$ ) pairs is driven up to $\sim 2.7$ from the value $\sim 2.5$ for the CB system. This elevation in DS may be ascribed to the modest effectiveness in steric hindrance of the propionyl group of medium size, relative to that of the more bulky butyryl group. Another factor expanding the miscible region in the map for the $\mathrm{CP}$ system is an intermolecular accessibility derived from the structural affinity of the propinonyl side-group with the VAc unit; this effect may be applicable to the blending pairs of CPs of DS > 2.3 and $\mathrm{P}(\mathrm{VP}-\mathrm{co}-\mathrm{VAc}) \mathrm{s}$ of $\mathrm{VP}=\mathrm{ca} .10-20 \mathrm{~mol} \%$.

\section{$<<$ Figure 7 $>>$}

Insight into the scale of homogeneous mixing

In the previous study on the CB/P(VP-co-VAc) system (Ohno and Nishio 2006), it was suggested that the degree of homogeneity for the combinations situated in the miscibility 
window was somewhat lower than that for the hydrogen-bonding type of miscible blends, reflecting a difference in absolute strength between the driving forces for the respective miscibility attainments. In this connection, we should remark that DSC thermograms for the 60/40-90/10 compositions of $\mathrm{CP}_{2.89} / \mathrm{P}\left(\mathrm{VP}_{0.10}-c o-\mathrm{VAc}_{0.90}\right)$ blends exhibited a single, but relatively broader glass transition (see Fig. 6b). A similar phenomenon was noted for other $\mathrm{CP} / \mathrm{P}(\mathrm{VP}-\mathrm{co}$-VAc) blends satisfying $\mathrm{DS}>2.7$ for the $\mathrm{CP}$ and $\mathrm{VP}=10-33 \mathrm{~mol} \%$ for the copolymer. Such a broadening in temperature range of the glass transition may be interpretable as due to mixing of plural microdomains with subtly different fluctuations in polymer composition (Lodge and McLeish 2000). In relation to this assumption, further investigations were made into the homogeneity of mixing for the $\mathrm{CP} / \mathrm{P}(\mathrm{VP}-c o-\mathrm{VAc})$ system by means of DMA and nuclear magnetic relaxation measurements.

\section{Thermal transition behavior evaluated by DMA}

As far as detection of $T_{\mathrm{g}}$ is concerned, DMA is more sensitive than calorimeric measurements in many cases of studies on multicomponent polymeric materials (Kusumi et al. 2011; MacKnight et al. 1978; Ultracki 1990). As a conventional matter, if DSC analysis is sensitive to heterogeneities with sizes of ca. 20-30 nm as an upper limit, DMA can detect a somewhat finer scale of heterogeneity, e.g., a domain size smaller than $\sim 15 \mathrm{~nm}$ (Kaplan 1976; Masson and Manley 1991; Nishio 1994).

Figure 8a shows the temperature dependence of the dynamic storage modulus $E^{\prime}$ and

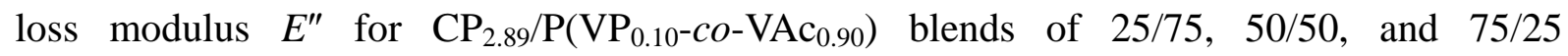
compositions, together with the corresponding data for plain $\mathrm{CP}_{2.89}$. As for the copolymer per se, the data was not obtained because of a brittle nature of the film. As demonstrated clearly in the figure, the unblended $\mathrm{CP}_{2.89}$ sample showed a very sharp transition with an $E^{\prime \prime}$ peak maximum at $137{ }^{\circ} \mathrm{C}$; this temperature is somewhat higher than $T_{\mathrm{g}}\left(127{ }^{\circ} \mathrm{C}\right)$ determined by DSC, however. In contrast, the blend samples gave a much broader $E^{\prime \prime}$ peak with a low 
onset point $\left(\sim 50{ }^{\circ} \mathrm{C}\right.$ in common), and a more gradual $E^{\prime}$ falling as well, in the glass transition temperature region, this trend being particularly prominent in the data for the $75 / 25$ and $50 / 50$ compositions.

\section{$\langle<$ Figure 8 (a) \& (b) $>>$}

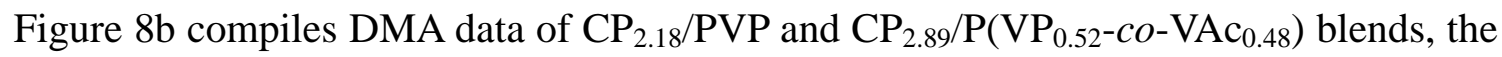
illustration for each series being restricted to a few samples rich in $\mathrm{CP}$ content, there. Any of the two blend series provided a single and sharp transition signal, both in the $E^{\prime \prime}$ peak and in the $E^{\prime}$ drop, which shifted systematically with polymer composition. From comparison with these data, the pair of $\mathrm{CP}_{2.89} / \mathrm{P}\left(\mathrm{VP}_{0.10}-c o-\mathrm{VAc}_{0.90}\right)$ described on ahead is obviously inferior in the degree of miscibility to the other two, within a scale $(\sim 15 \mathrm{~nm})$ detectable by DMA. Incidentally, it is interesting to find a homogeneity on the DMA scale for the $\mathrm{CP}_{2.89}$ blends with $\mathrm{P}\left(\mathrm{VP}_{0.52}-\mathrm{co}-\mathrm{VAc}_{0.48}\right)$ having equimolar amounts of $\mathrm{VP}$ and VAc units, although the blending pair is not of the hydrogen-bonding type such as the $\mathrm{CP}_{2.18} / \mathrm{PVP}$ one but situated in the miscibility window of that map (Fig. 7).

\section{Homogeneity estimated by solid-state ${ }^{13} \mathrm{C} N \mathrm{NR}$ relaxation}

As a useful technique in solid-sate ${ }^{13} \mathrm{C}$ NMR, $T_{1 \rho}{ }^{\mathrm{H}}$ measurements for specific carbons in a multicomponent polymer system make it possible to estimate the mixing homogeneity in a scale of ${ }^{1} \mathrm{H}$ spin-diffusion length that is usually within several nanometers (Masson and Manley 1991; Ohno et al. 2005; Zhang et al. 1992). $\quad T_{1 \rho}{ }^{\mathrm{H}}$ values can be obtained by fitting the decaying carbon resonance intensity to the following exponential equation:

$$
M(\tau)=M(0) \exp \left(-\tau / T_{1 \rho}{ }^{\mathrm{H}}\right)
$$

where $M(\tau)$ is the magnetization intensity observed as a function of the spin-locking time $\tau$. In a general rule, if two constituent polymers are in a homogeneously mixed state on the scale over which ${ }^{1} \mathrm{H}$ spin-diffusion can take place in a time $T_{1 \rho}{ }^{\mathrm{H}}$, the $T_{1 \rho}{ }^{\mathrm{H}}$ values for different protons belonging to the respective components may be equalized to each other by the spin 
diffusion.

In terms of the NMR technique, a comparative assessment of the polymer-polymer

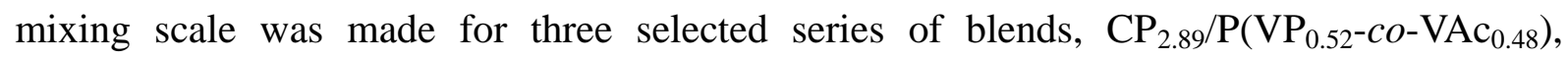
$\mathrm{CP}_{1.71} / \mathrm{P}\left(\mathrm{VP}_{0.52}-c o-\mathrm{VAc}_{0.48}\right)$, and $\mathrm{CP}_{1.71} / \mathrm{PVP}$. Figure 9 exemplifies ${ }^{13} \mathrm{C} \mathrm{CP} / \mathrm{MAS}$ spectra obtained for $\mathrm{CP}_{2.89}, \mathrm{P}\left(\mathrm{VP}_{0.52}-c o-\mathrm{VAc}_{0.48}\right)$, and their 50/50 blend. The peak assignments of the spectra are based on literature data for CP (Tezuka and Tsuchiya 1995), PVP (Zhang et al. 1992), and PVAc (Cheung et al. 2000). The experiment of $T_{1 \rho}{ }^{\mathrm{H}}$ quantifications was done through monitoring the following ${ }^{13} \mathrm{C}$ resonance signals with better resolution: $\mathrm{C} 2 / \mathrm{C} 3 / \mathrm{C} 5$ pyranose carbons (74 ppm) and propionyl carbons $\mathrm{C} 8(28 \mathrm{ppm})$ and $\mathrm{C} 9(9.3 \mathrm{ppm})$ for the $\mathrm{CP}$ component, and $\mathrm{C}_{\mathrm{b}} / \mathrm{C}_{\mathrm{c}}(42 \mathrm{ppm})$ and $\mathrm{C}_{\delta} / \mathrm{C}_{\mathrm{d}}$ carbons $(\sim 20 \mathrm{ppm})$ for the $\mathrm{P}(\mathrm{VP}-\mathrm{co}-\mathrm{VAc})$ component. Figure 10a illustrates the decay behaviour in intensity of the C2/C3/C5 and $\mathrm{C}_{\mathrm{b}} / \mathrm{C}_{\mathrm{c}}$ peaks for unblended $\mathrm{CP}_{2.89}$ and $\mathrm{P}\left(\mathrm{VP}_{0.52}-c o-\mathrm{VAc}_{0.48}\right)$, respectively, and for their $50 / 50$ blend imparting both resonance signals as well. The slope of each semi-logarithmic plot corresponds to an inverse of $T_{1 \rho}{ }^{\mathrm{H}}$ as the time constant of the relaxation process. We found from these plots that $T_{1 \rho}{ }^{\mathrm{H}}$ of $\mathrm{CP}_{2.89}(18.5 \mathrm{~ms})$ increased to $22.7 \mathrm{~ms}$ and that of $\mathrm{P}\left(\mathrm{VP}_{0.52}-\mathrm{co}-\mathrm{VAc}_{0.48}\right)(35.4 \mathrm{~ms})$ decreased to $33.1 \mathrm{~ms}$ by the $50 / 50$ blending, but they never became so close to each other. Regarding the $\mathrm{CP}_{1.71} / \mathrm{P}\left(\mathrm{VP}_{0.52}-\mathrm{co}-\mathrm{VAc}_{0.48}\right)$ pair (Fig. 10b), on the contrary, $T_{1 \rho}{ }^{\mathrm{H}}$ values of the two components for the 50/50 blend coincided with each other just at the midpoint $(27.9 \mathrm{~ms})$ between the respective original values, $20.5 \mathrm{~ms}$ for $\mathrm{CP}_{1.71}$ and $35.4 \mathrm{~ms}$ for the copolymer. A similar tendency of $T_{1 \rho}{ }^{\mathrm{H}}$ variations was observed in tracing of another set of the $\mathrm{C} 8$ or $\mathrm{C} 9$ signal of $\mathrm{CP}$ and the $\mathrm{C}_{\delta} / \mathrm{C}_{\mathrm{d}}$ signal of $\mathrm{P}(\mathrm{VP}-\mathrm{co}-\mathrm{VAc})$.

\section{$<<$ Figure 9 $>>$}

\section{$<<$ Figure 10 (a) \& (b) $>>$}

Table 2 lists all the $T_{1 \rho}{ }^{\mathrm{H}}$ data obtained for $\mathrm{CP}_{1.71}, \mathrm{CP}_{2.89}, \mathrm{PVP}, \mathrm{P}\left(\mathrm{VP}_{0.52}-c o-\mathrm{VAc}_{0.48}\right)$, and their miscible blends of $\mathrm{CP} /$ vinyl polymer $=75 / 25-25 / 75$. In the $\left.\mathrm{CP}_{1.71} / \mathrm{P}_{\left(\mathrm{VP}_{0.52}-\text { co- }\right.}-\mathrm{VAc}_{0.48}\right)$ series, $T_{1 \rho}{ }^{\mathrm{H}}$ of the $\mathrm{CP}_{1.71}$ component, originally $20.0 \mathrm{~ms}$ as an average, rises systematically 
397

398

399

400

401

402

403

404

405

406

407

408

409

410

411

412

413

414

415

416

with an increase in the copolymer content, while that of the $\mathrm{P}\left(\mathrm{VP}_{0.52}-\mathrm{co}-\mathrm{VAc}_{0.48}\right)$ component, originally $35.0 \mathrm{~ms}$ as an average, diminishes correspondingly with increasing $\mathrm{CP}_{1.71}$ content. In consequence, the two $T_{1 \rho}{ }^{\mathrm{H}} \mathrm{S}$ at every blend composition are surely in good agreement with each other. Such a composition-dependent shift of the almost equalized $T_{1 \rho}{ }^{{ }^{H}} \mathrm{~S}$ of two components is also observed for the $\mathrm{CP}_{1.71} / \mathrm{PVP}$ blend series. Thus, it is reasonably deduced that the two constituent polymers in the two series of blends are intimately mixed within a range where the mutual ${ }^{1} \mathrm{H}$-spin diffusion is permitted over a period of the respective homogenized $T_{1 \rho}{ }^{\mathrm{H}}$, e.g., $\sim 30.5 \mathrm{~ms}$ for the 50/50 composition of $\mathrm{CP}_{1.71} / \mathrm{PVP}$.

\section{$<<$ Table 2>>}

An effective path length $L$ of the spin diffusion in a time $T_{1 \rho}{ }^{\mathrm{H}}$ is given by the following equation (McBrierty and Douglass 1981):

$$
L \cong\left(6 D T_{1 \rho}{ }^{\mathrm{H}}\right)^{1 / 2}
$$

where $D$ is the spin-diffusion coefficient, usually taken to be $\sim 1.0 \times 10^{-12} \mathrm{~cm}^{2} / \mathrm{s}$ in organic polymer materials. By adopting $T_{1 \rho}{ }^{\mathrm{H}}$ data of $23-31 \mathrm{~ms}$ approximated for the $\mathrm{CP}_{1.71} / \mathrm{P}\left(\mathrm{VP}_{0.52}-\right.$ co- $\left.\mathrm{VAc}_{0.48}\right)$ blends of $75 / 25-25 / 75$ compositions, the diffusion path length is calculated as $L=3.7-4.3 \mathrm{~nm}$. In a similar manner, $L$ is determined to be $3.9-4.4 \mathrm{~nm}$ with $T_{1 \rho}{ }^{\mathrm{H}}=25-33 \mathrm{~ms}$ for the corresponding $\mathrm{CP}_{1.71} / \mathrm{PVP}$ compositions. Accordingly, it is confirmed that any of these miscible blends using a low-substituted CP is virtually homogeneous in a scale of ca. $4 \mathrm{~nm}$.

With regard to the $\mathrm{CP}_{2.89} / \mathrm{P}\left(\mathrm{VP}_{0.52}-\mathrm{co}-\mathrm{VAc}_{0.48}\right)$ series, as evidenced in Table 2, there arises a serious disagreement between $T_{1 \rho}{ }^{\mathrm{H}} \mathrm{S}$ of the two polymer components at every blend composition, although the mutual approach to a small extent is admitted. This larger temporal disagreement implies that the relaxation processes of the two polymers in the blends proceeded rather independently without their cooperative spin diffusion. By the combined use of this result and the previous DMA one, it can be concluded that the scale of

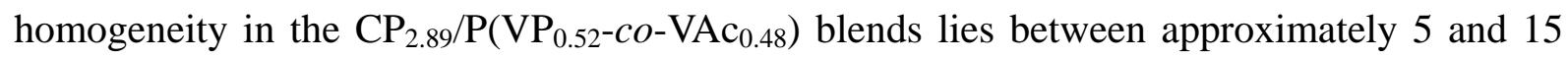


nm.

\section{Conclusions}

Miscibility characterization was performed on blends of cellulose propionate (CP) with synthetic vinyl polymers containing $N$-vinyl pyrrolidone (VP) and/or vinyl acetate (VAc) units, i.e., PVP, PVAc, and P(VP-co-VAc) random copolymers. On the basis of $T_{\mathrm{g}}$ analysis by DSC, a miscibility map (Fig. 7) was successfully constructed as a function of both the propionyl DS of CP and the VP:VAc composition of P(VP-co-VAc). FT-IR spectroscopy was also utilized to detect a hydrogen-bonding type of intermolecular interaction contributory to the miscibility attainment. As denoted in that map, polymer pairs of $\mathrm{CP} / \mathrm{P}(\mathrm{VP}-\mathrm{co}$-VAc) satisfying DS $<2.7$ for the CP component and VP > $20 \mathrm{~mol} \%$ for the vinyl polymer component were miscible. This miscibility is given rise to, more or less, by virtue of the hydrogen bonding between CP-hydroxyls and VP-carbonyls, and hence the effectiveness should be greater when the propionyl DS is lower and the VP fraction is higher. The upper limit of DS $=2.7$ required for the miscibility was intermediate between the corresponding ones, acetyl DS $=2.8$ and butyryl DS $=2.5$, for the comparable systems employing cellulose acetate (CA) and butyrate (CB). This observation can be explained as being due to the difference in bulkiness between the three sorts of acyl substituents, each exerting an effect of steric hindrance to decline the hydrogen-bonding interaction.

CPs of DS > 2.7 exhibited miscibility with $\mathrm{P}(\mathrm{VP}-\mathrm{co}-\mathrm{VAc}) \mathrm{s}$ of $\mathrm{VP}=10-65 \mathrm{~mol} \%$, despite their imperfect miscibility with both PVP and PVAc homopolymres; this resulted in advent of a definite 'miscibility window' in the map, as has been experienced formerly in our study of $\mathrm{CB} / \mathrm{P}(\mathrm{VP}-\mathrm{co}-\mathrm{VAc})$ blends. The behaviour may be interpreted to be occasioned principally by intramolecular repulsion between the comonomer units in $\mathrm{P}(\mathrm{VP}-\mathrm{co}$-VAc). In addition, another effect, the structural affinity between the propionyl side-group and the VAc 
unit, contributes to the miscibility realized for blends of highly propionylated CPs (DS > 2.3) with VAc-rich copolymers (VP:VAc $=10: 90-33: 67) . \quad$ Eventually, the miscible pairing region extended more widely in the map for the CP/P(VP-co-VAc) system, compared with the situations in the corresponding blend systems using CA and CB. It is astonishing afresh to find that only one difference in carbon number of the acyl substitution drastically changed the miscibility behaviour of cellulose esters (CEs) with a given synthetic copolymer.

However, caution should be exercised to the scale of homogeneity in the $\mathrm{CP} / \mathrm{P}(\mathrm{VP}-\mathrm{co}$-VAc) blends being estimated to form a miscible monophase. As a result of further investigation by DMA and $T_{1 \rho}{ }^{\mathrm{H}}$ quantifications in solid-state ${ }^{13} \mathrm{C}$ NMR, we had awareness of the following respects: The miscible blends of hydrogen-bonding type are completely homogeneous on a scale of a few nanometers $(\leq 4 \mathrm{~nm})$, whereas the blend series situated in the miscibility window are homogeneous with a possible microdomain size between ca. 5 and $15 \mathrm{~nm}$. In the latter assessment, $\mathrm{CP}$ blends with $\mathrm{P}(\mathrm{VP}-\mathrm{co}$-VAc)s extremely rich in VAc (e.g., VP:VAc $=10: 90)$ are excepted from the relevant group, their miscibility being invited by a rather weak interaction due to the structural affinity effect. The blends of exception can contain heterogeneous domains of ca. 15-20 nm sizes as a tentative estimate.

From a practical standpoint, these results will contribute toward expanding the opportunities of material design based on the CE family. Further studies along this line of fundamental characterization are now in progress for CE blends with other vinyl copolymers, in parallel with inquiries into their functionalities as optical and/or membrane materials. In the not too distant future, our effort will also be made to investigate an effect of regioselectivity of the acyl substituent in CEs on their miscibility with synthetic polymers, beyond the discussion in terms of the average DS parameter.

\section{Reference}


Cheung MK, Wang J, Zheng S, Mi Y (2000) Miscibility of poly(epichlorohydrin)/poly(vinyl acetate) blends investigated with high-resolution solid-state ${ }^{13} \mathrm{C}$ NMR. Polymer 41:1469-1474

Edgar KJ, Buchanan CM, Debenham JS, Rundquist PA, Seiler BD, Shelton MC, Tindall D (2001) Advances in cellulose ester performance and application. Prog Polym Sci 26:1605-1688

Fox TG, Flory PJ (1954) The glass transition temperature and related properties of polystyrene. Influence of molecular weight. J Polym Sci 14:315-319

Kaplan DS (1976) Structure-property relationships in copolymers to composites: molecular interpretation of the glass transition phenomenon. J Appl Polym Sci 20:2615-2629

Kusumi R, Inoue Y, Shirakawa M, Miyashita Y, Nishio Y (2008) Cellulose alkyl ester/poly( $\varepsilon$-caprolactone) blends: characterization of miscibility and crystallization behaviour. Cellulose 15:1-16

Kusumi R, Teramoto Y, Nishio Y (2011) Structural characterization of poly( $\varepsilon$-caprolactone)-grafted cellulose acetate and butyrate by solid-state ${ }^{13} \mathrm{C} N M R$, dynamic mechanical, and dielectric relaxation analyses. Polymer 52:5912-5921

Lodge TP, McLeish TCB (2000) Self-concentrations and effective glass transition temperatures in polymer blends. Macromolecules 33:5278-5284

MacKnight WJ, Karasz FE, Fried JR (1978) Solid state transition behaviour of blends, chap. 5. In: Paul DR, Newman S (eds) Polymer blends, vol 1. Academic Press, New York, pp $185-242$

Marchessault RH, Liang CY (1960) Infrared spectra of crystalline polysaccharides. III. Marcerized cellulose. J Polym Sci 43:71-84

Masson JF, Manley RS (1991) Miscible blends of cellulose and poly(vinylpyrrolidone). Macromolecules 24:6670-6679

McBrierty VJ, Douglass DC (1981) Recent advances in the NMR of solid polymers. J Polym 
502

503

504

505

506

507

508

509

510

Miyashita Y, Suzuki T, Nishio Y (2002) Miscibility of cellulose acetate with vinyl polymers. Cellulose 9: 215-223

Nandi AK, MAndal BM, Bhattacharyya SN (1985) Miscibility of poly(methyl acrylate) and poly(vinyl acetate): Incompatibility in solution and thermodynamic characterization by inverse gas chromatography. Macromolecules 18:1454-1460

Nishio Y (1994) Hyperfine composites of cellulose with synthetic polymers, chap. 5. In: Gilbert RD (ed) Cellulosic polymers, blends and composites. Hanser, Munich, pp 95-113

Nishio Y (2006) Material functionalization of cellulose and related polysaccharides via diverse microcompositions. Adv Polym Sci 205:97-151

Nishio Y, Matsuda K, Miyashita Y, Kimura N, Suzuki H (1997) Blends of poly(E-caprolactone) with cellulose alkyl esters: effect of the alkyl side-chain length and degree of substitution on miscibility. Cellulose 4:131-145

Ohno T, Nishio Y (2006) Cellulose alkyl ester/vinyl polymer blends: effects of butyryl substitution and intramolecular copolymer composition on the miscibility. Cellulose $13: 245-259$

Ohno T, Nishio Y (2007) Estimation of miscibility and interaction for cellulose acetate and butyrate blends with $N$-vinylpyrrolidone copolymers. Macromol Chem Phys 208:622-634

Ohno T, Yoshizawa S, Miyashita Y, Nishio Y (2005) Interaction and scale of mixing in cellulose acetate/poly( $N$-vinyl pyrrolidone-co-vinyl acetate) blends. Cellulose $12: 281-291$

Seferis JC (1999) Refractive indices of polymers. In: Brandrup J, Immergut EH, Grulke EA (eds) Polymer Handbook, 4th edn. Wiley-Interscience, New York, pp 571-582

Takegoshi K, Ohya Y, Hikichi K (1993) Miscibility and inter-polymer interactions of the poly(methyl acrylate)/poly(vinyl acetate) blend as studied by NMR in solution. Polym J 
528 Tezuka Y, Tsuchida Y (1995) Determination of substituent distribution in cellulose acetate by 529 means of a ${ }^{13} \mathrm{C}$ NMR study on its propanoated derivative. Carbohydrate Research 273:83-91

531 Utracki LA (1990) Polymer alloys and blends: therymodynamics and rheology. Hanser, $532 \quad$ Munich

533 Zhang XQ, Takegoshi K, Hikichi K (1992) High-resolution solid-state C-13 nuclear magnetic resonance study on poly(vinyl alcohol)/poly(vinylpyrrolidone) blends. Polymer

535 33:712-717

536 
Fig. 1 Miscibility maps for two blend systems (a) CA/P(VP-co-VAc) and (b) 2006) in a rearranged style retaining the essence.

Fig. 2 DSC thermograms obtained for (a) $\mathrm{CP}_{2.72} / \mathrm{PVP}$ and (b) $\mathrm{CP}_{2.62} / \mathrm{PVP}$ blends. Arrows indicate a $T_{\mathrm{g}}$ position taken as the midpoint of a baseline shift in heat flow.

Fig. 3 FT-IR spectra of $\mathrm{CP}_{1.71}$, PVP, and their blends in the frequency regions of (a) $\mathrm{O}-\mathrm{H}$ and (b) $\mathrm{C}=\mathrm{O}$ stretching vibrations. Solid arrows indicate a peak-top position in the respective specific absorption bands, and white arrows indicate a shoulder band associated with hydrogen bonding (see text for discussion).

Fig. $4 T_{\mathrm{g}}$ versus composition plots for eight series of CP/PVAc blends. DS of CP: $\bigcirc, 1.90$;

Fig. 5 Composition dependence of $T_{\mathrm{g}}$ for eight series of $\mathrm{CP}_{1.90} / \mathrm{P}(\mathrm{VP}-$ co-VAc $)$ blends. 73:27; $\bigcirc, 87: 13$.

Fig. 6

DSC thermograms obtained for

(a) $\mathrm{CP}_{2.89} / \mathrm{P}\left(\mathrm{VP}_{0.52}-c o-\mathrm{VAc}_{0.48}\right)$ and $\mathrm{CP}_{2.89} / \mathrm{P}\left(\mathrm{VP}_{0.10^{-}}\right.$co- $\left.\mathrm{VAc}_{0.90}\right)$ blends. Arrows indicate a $T_{\mathrm{g}}$ position.

Fig. 7 Miscibility map for $\mathrm{CP} / \mathrm{P}(\mathrm{VP}-\mathrm{co}-\mathrm{VAc})$ blends, as a function of DS of $\mathrm{CP}$ and VP 
563 miscible $(\bigcirc)$, immiscible $(\times)$, or partially miscible $(\triangle)$.

564

565

566

567

568

569

570

571

572

573

574

575

576

577

578 In addition to the ten figures, there are two tables. See annexed sheets. (a) $\mathrm{CP}_{2.89} / \mathrm{P}\left(\mathrm{VP}_{0.10}-c o-\mathrm{VAc}_{0.90}\right)$ and (b) $\mathrm{CP}_{2.18} / \mathrm{PVP}$ and $\mathrm{CP}_{2.89} / \mathrm{P}\left(\mathrm{VP}_{0.52}-c o-\mathrm{VAc}_{0.48}\right)$ blends. 50/50 blend. copolymer (see Fig. 9).

Fig. 8 Temperature dependence of the dynamic storage modulus $E^{\prime}$ and loss modulus $E^{\prime \prime}$ for

Fig. 9 Solid-state ${ }^{13} \mathrm{C} \mathrm{CP} / \mathrm{MAS} \mathrm{NMR}$ spectra for $\mathrm{CP}_{2.89}, \mathrm{P}\left(\mathrm{VP}_{0.52}-\mathrm{co}-\mathrm{VAc}_{0.48}\right)$, and their

Fig. 10 Semilogarithmic plots of the decay of ${ }^{13} \mathrm{C}$ resonance intensities as a function of spin-locking time $\tau$, for solid films of (a) $\mathrm{CP}_{2.89}, \mathrm{P}\left(\mathrm{VP}_{0.52}-\right.$ co- $\left.\mathrm{VAc}_{0.48}\right)$, and their 50/50 blend,

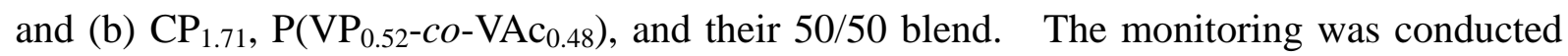
for the peak intensity of $\mathrm{C} 2 / \mathrm{C} 3 / \mathrm{C} 5$ pyranose carbons of $\mathrm{CP}$ and that of $\mathrm{C}_{\mathrm{b}} / \mathrm{C}_{\mathrm{c}}$ carbons of the 
579 Table 1 Characterization of CP and synthetic vinyl polymers used in the present study

\begin{tabular}{|c|c|c|c|c|c|c|}
\hline Sample & $\mathrm{DS}^{a}$ & $M_{\mathrm{w}}^{b}$ & $M_{\mathrm{n}}^{b}$ & $M_{\mathrm{w}} / M_{\mathrm{n}}^{b}$ & $T_{\mathrm{g}} /{ }^{\circ} \mathrm{C}$ & Source \\
\hline \multirow[t]{10}{*}{$\mathrm{CP}$} & 1.71 & $2,010,000$ & 850,000 & 2.36 & 162 & Synthesized \\
\hline & 1.90 & $1,860,000$ & 824,000 & 2.26 & 161 & Synthesized \\
\hline & 2.18 & $1,300,000$ & 577,000 & 2.25 & 157 & Synthesized \\
\hline & 2.35 & $2,210,000$ & 925,000 & 2.39 & 153 & Synthesized \\
\hline & 2.54 & $1,180,000$ & 509,000 & 2.32 & 140 & Synthesized \\
\hline & 2.62 & 979,000 & 359,000 & 2.73 & 138 & Synthesized \\
\hline & 2.72 & $2,390,000$ & 968,000 & 2.47 & 134 & Synthesized \\
\hline & 2.81 & $1,990,000$ & 837,000 & 2.38 & 128 & Synthesized \\
\hline & 2.89 & $2,000,000$ & 692,000 & 2.89 & 127 & Synthesized \\
\hline & 2.93 & $1,250,000$ & 525,000 & 2.38 & 124 & Synthesized \\
\hline Sample & $\mathrm{VP}$ content $/ \mathrm{mol} \%^{a}$ & $M_{\mathrm{w}}{ }^{c}$ & $M_{\mathrm{n}}{ }^{c}$ & $M_{\mathrm{w}} / M_{\mathrm{n}}^{c}$ & $T_{\mathrm{g}} /{ }^{\circ} \mathrm{C}$ & Source \\
\hline PVP & 100 & $360,000^{d}$ & - & - & 177 & Nacalai Tesque, Inc. \\
\hline \multirow[t]{8}{*}{$\mathrm{P}(\mathrm{VP}-c o-\mathrm{VAc})$} & 87 & 56,500 & 28,000 & 2.02 & 124 & Synthesized $^{e}$ \\
\hline & 73 & 52,100 & 25,000 & 2.08 & 111 & Synthesized $^{e}$ \\
\hline & 62 & 51,600 & 24,400 & 2.11 & 101 & Synthesized $^{e}$ \\
\hline & 52 & 28,000 & 5,120 & 5.47 & 89 & Polyscience, Inc. ${ }^{f}$ \\
\hline & 40 & 51,100 & 20,700 & 2.47 & 76 & Synthesized $^{e}$ \\
\hline & 33 & 23,300 & 3,800 & 6.12 & 72 & Polyscience, Inc. ${ }^{f}$ \\
\hline & 23 & 59,400 & 26,100 & 2.27 & 55 & Synthesized $^{e}$ \\
\hline & 10 & 46,500 & 27,700 & 1.68 & 45 & Synthesized $^{e}$ \\
\hline PVAc & 0 & $90,000^{d}$ & - & - & 41 & Polyscience, Inc. \\
\hline
\end{tabular}

${ }^{a}$ Determined by ${ }^{1} \mathrm{H}$ NMR.

${ }^{b}$ Determined by gel permeation chromatography (mobile phase, tetrahydrofuran at $40{ }^{\circ} \mathrm{C}$ ) with polystyrene standards.

${ }^{c}$ Determined by gel permeation chromatography (mobile phase, $10 \mathrm{mM} / \mathrm{L}$ lithium bromide $/ N, N$-dimethylformamide at $40{ }^{\circ} \mathrm{C}$ ) with polystyrene standards.

${ }^{d}$ Nominal value.

${ }^{e}$ Synthesized in our laboratory by radical polymerization of two distilled monomers, VP (Aldrich Chemical Co.) and VAc (Nacalai Tesque, Inc.), in the same way as that described in a previous paper (Miyashita et al. 2002).

${ }^{f}$ Used after purification by dissolution in dichloromethane and reprecipitation into petroleum ether. 
581 Table $2 T_{1 \rho}{ }^{\mathrm{H}}$ values obtained for three series of blends, $\mathrm{CP}_{2.89} / \mathrm{P}\left(\mathrm{VP}_{0.52}-\right.$ co- $\left.-\mathrm{VAc}_{0.48}\right)$,

$582 \quad \mathrm{CP}_{1.71} / \mathrm{P}\left(\mathrm{VP}_{0.52}-c o-\mathrm{VAc}_{0.48}\right)$, and $\mathrm{CP}_{1.71} / \mathrm{PVP}$

\begin{tabular}{|c|c|c|c|c|c|c|c|}
\hline \multirow{3}{*}{$\begin{array}{c}\mathrm{CP}_{2.89} / \mathrm{P}\left(\mathrm{VP}_{0.52}-c o-\mathrm{VAc}_{0.48}\right) \\
(\mathrm{wt} / \mathrm{wt})\end{array}$} & \multicolumn{7}{|c|}{$T_{1 \rho}^{\mathrm{H}} / \mathrm{ms}$} \\
\hline & \multicolumn{4}{|c|}{$\mathrm{CP}_{2.89}$} & \multicolumn{3}{|c|}{$\mathrm{P}\left(\mathrm{VP}_{0.52}-c o-\mathrm{VAc}_{0.48}\right)$} \\
\hline & $\mathrm{C} 2 / 3 / 5$ & $\mathrm{C} 8$ & C9 & Ave. & $\mathrm{b} / \mathrm{c}$ & $\delta / d$ & Ave. \\
\hline $100 / 0$ & 18.5 & 17.6 & 17.7 & 17.9 & - & - & - \\
\hline $75 / 25$ & 20.3 & 18.8 & 18.0 & 19.0 & 32.9 & 29.7 & 31.3 \\
\hline $50 / 50$ & 22.7 & 20.5 & 19.2 & 20.8 & 33.1 & 30.9 & 32.0 \\
\hline $25 / 75$ & 25.3 & 22.6 & 21.2 & 23.0 & 34.7 & 33.8 & 34.3 \\
\hline $0 / 100$ & - & - & - & - & 35.4 & 34.6 & 35.0 \\
\hline \multirow{3}{*}{$\begin{array}{c}\mathrm{CP}_{1.71} / \mathrm{P}\left(\mathrm{VP}_{0.52}-c o-\mathrm{VAc}_{0.48}\right) \\
(\mathrm{wt} / \mathrm{wt})\end{array}$} & \multicolumn{7}{|c|}{$T_{1 \rho}{ }^{\mathrm{H}} / \mathrm{ms}$} \\
\hline & \multicolumn{4}{|c|}{$\mathrm{CP}_{1.71}$} & \multicolumn{3}{|c|}{$\mathrm{P}\left(\mathrm{VP}_{0.52}-c o-\mathrm{VAc}_{0.48}\right)$} \\
\hline & $\mathrm{C} 2 / 3 / 5$ & $\mathrm{C} 8$ & C9 & Ave. & $\mathrm{b} / \mathrm{c}$ & $\delta / d$ & Ave. \\
\hline $100 / 0$ & 20.5 & 20.3 & 19.2 & 20.0 & - & - & - \\
\hline $75 / 25$ & 24.3 & 23.0 & 21.6 & 23.0 & 24.5 & 24.1 & 24.3 \\
\hline $50 / 50$ & 27.8 & 26.8 & 24.5 & 26.4 & 27.9 & 26.9 & 27.4 \\
\hline $25 / 75$ & 33.0 & 29.7 & 27.8 & 30.2 & 33.7 & 30.9 & 32.3 \\
\hline $0 / 100$ & - & - & - & - & 35.4 & 34.6 & 35.0 \\
\hline \multirow{3}{*}{$\begin{array}{l}\mathrm{CP}_{1.71} / \mathrm{PVP} \\
(\mathrm{wt} / \mathrm{wt})\end{array}$} & \multicolumn{7}{|c|}{$T_{1 \rho}^{\mathrm{H}} / \mathrm{ms}$} \\
\hline & \multicolumn{4}{|c|}{$\mathrm{CP}_{1.71}$} & \multicolumn{3}{|c|}{ PVP } \\
\hline & $\mathrm{C} 2 / 3 / 5$ & $\mathrm{C} 8$ & C9 & Ave. & $\mathrm{b} / \mathrm{c}$ & $\mathrm{d}$ & Ave. \\
\hline $100 / 0$ & 20.5 & 20.3 & 19.2 & 20.0 & - & - & - \\
\hline $75 / 25$ & 25.1 & 24.1 & 23.0 & 24.1 & 26.0 & 26.0 & 26.0 \\
\hline $50 / 50$ & 30.9 & 30.1 & 30.8 & 30.6 & 30.6 & 29.5 & 30.1 \\
\hline $25 / 75$ & 33.4 & 33.7 & 33.1 & 33.4 & 33.7 & 33.0 & 33.4 \\
\hline $0 / 100$ & - & - & - & - & 32.6 & 31.3 & 32.0 \\
\hline
\end{tabular}


(a)

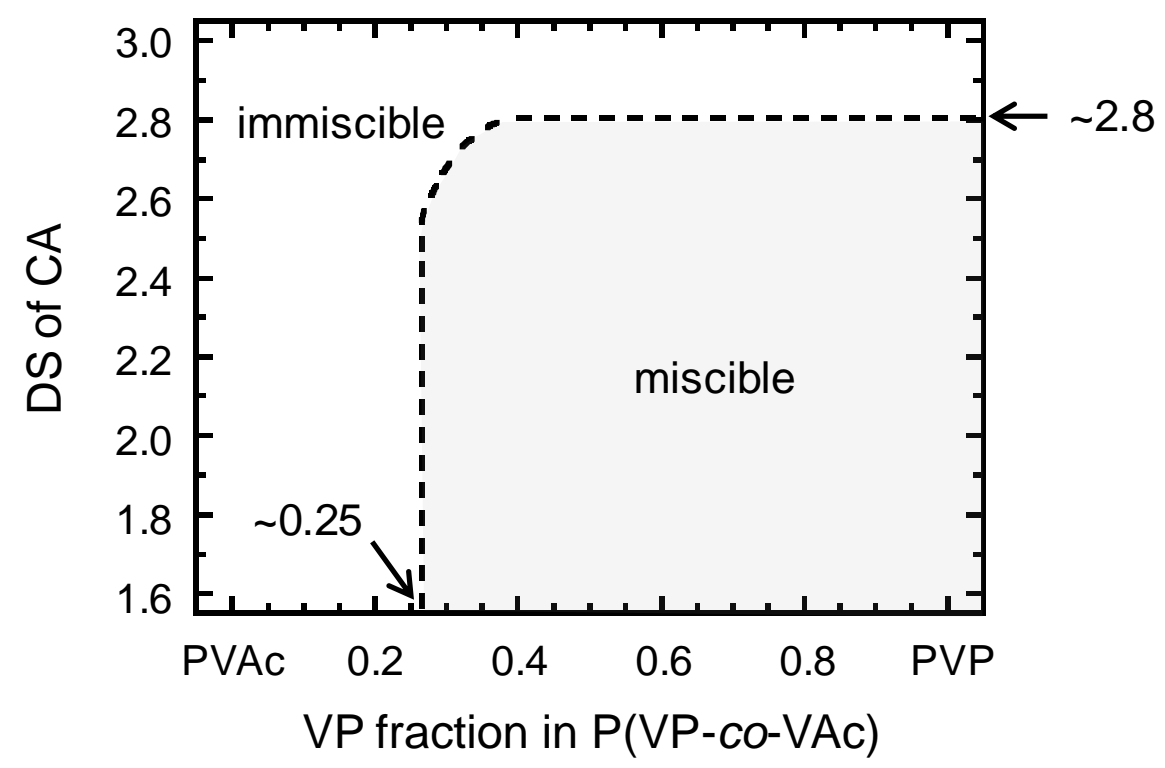

584

(b)

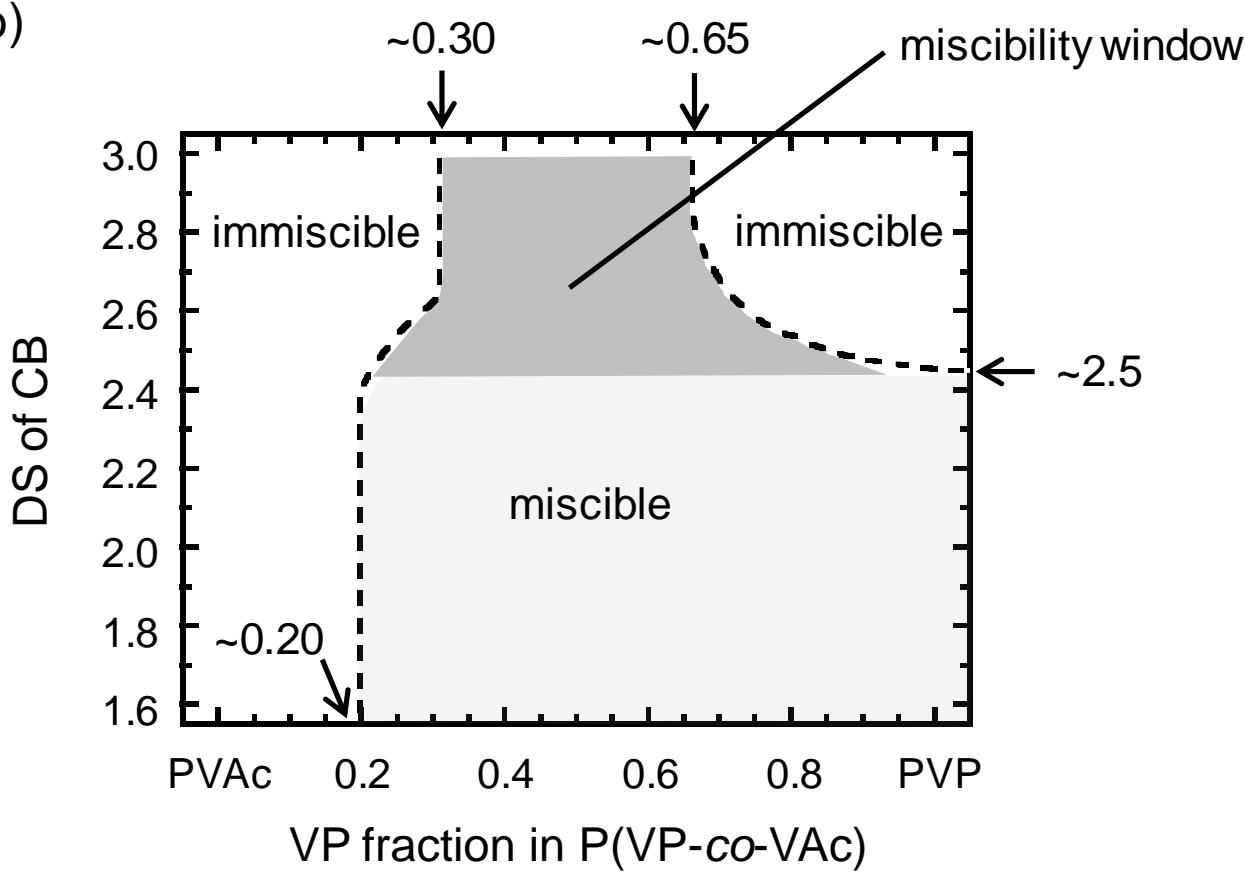

Fig. 1 Miscibility maps for two blend systems

(a) $\mathrm{CA} / \mathrm{P}(\mathrm{VP}-\mathrm{co}-\mathrm{VAc})$ and (b) $\mathrm{CB} / \mathrm{P}(\mathrm{VP}-\mathrm{co}$-VAc), quoted from previous papers (Miyashita et al. 2002; Ohno and Nishio 2006) in a rearranged style retaining the essence. 
(a)

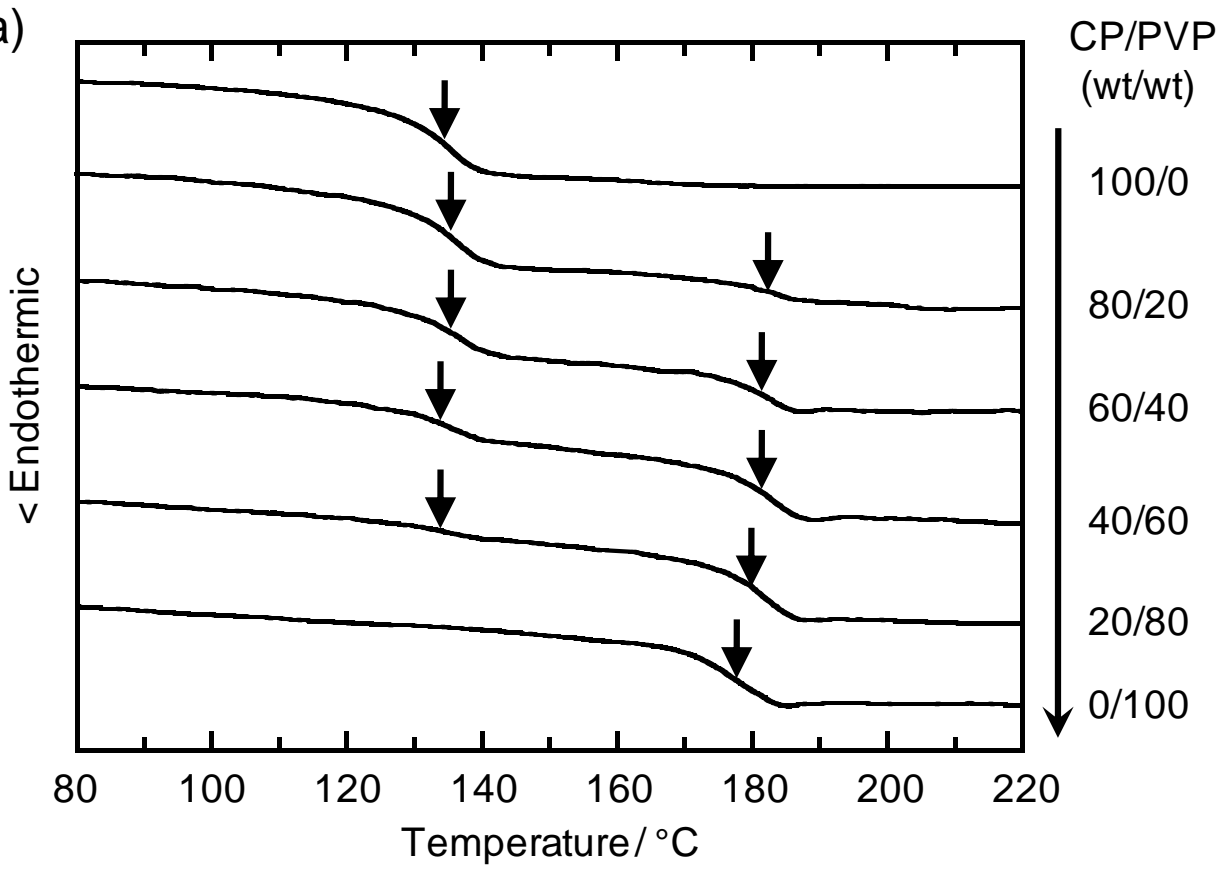

(b)

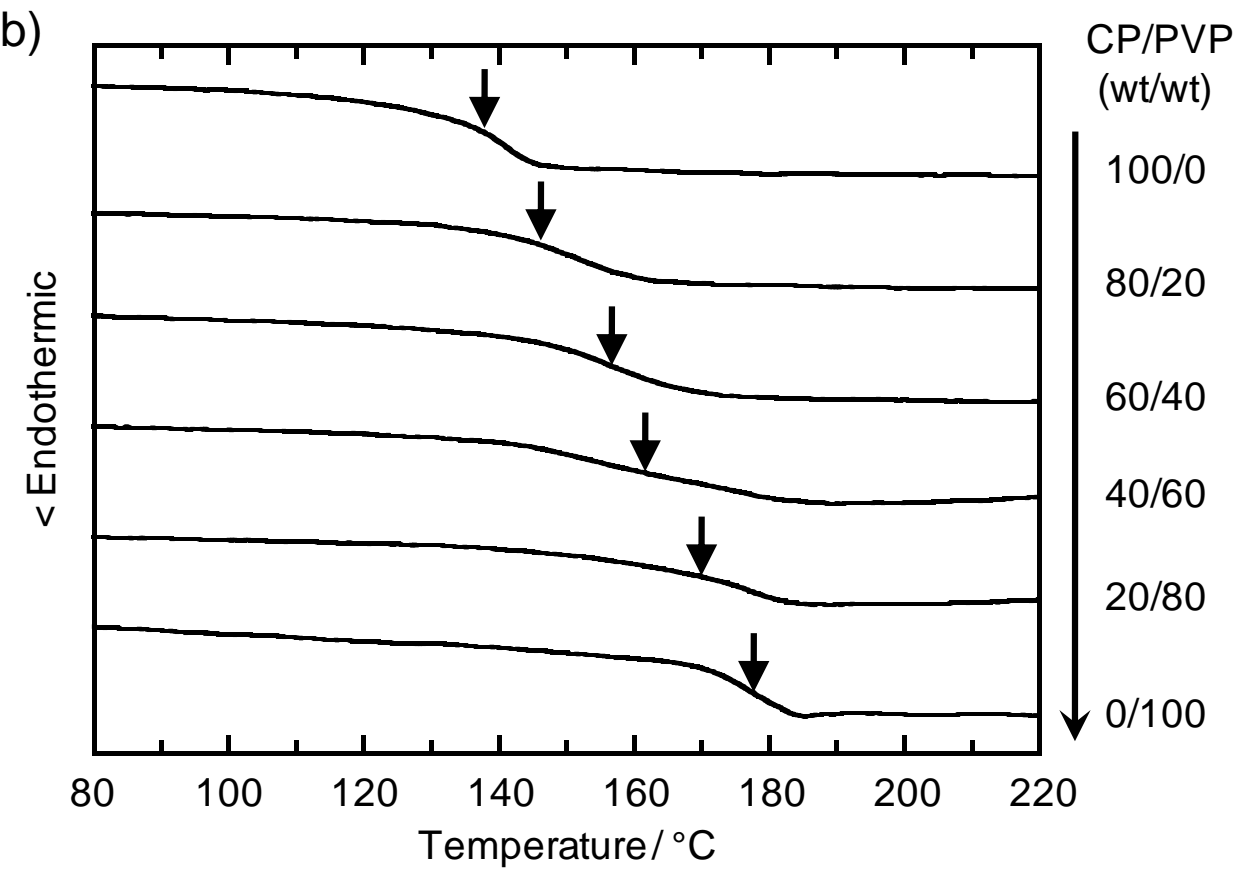

595 Fig. 2 DSC thermograms obtained for (a) $\mathrm{CP}_{2.72} / \mathrm{PVP}$ and (b) $\mathrm{CP}_{2.62} / \mathrm{PVP}$ blends. Arrows 596 indicate a $T_{\mathrm{g}}$ position taken as the midpoint of a baseline shift in heat flow. 
(a)

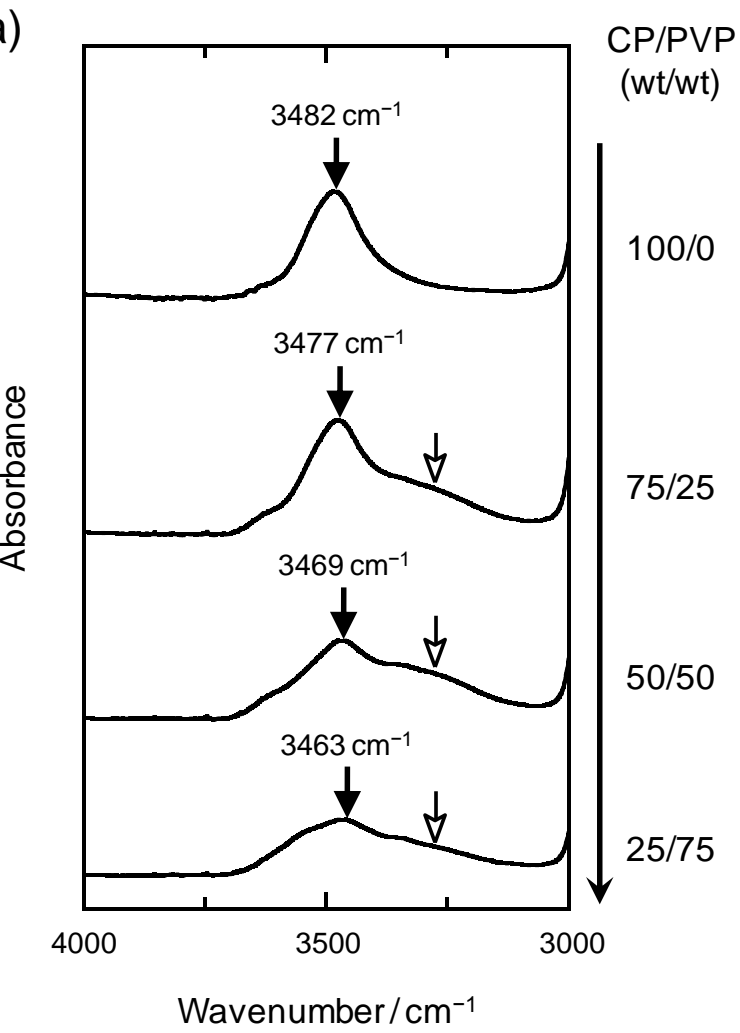

(b)

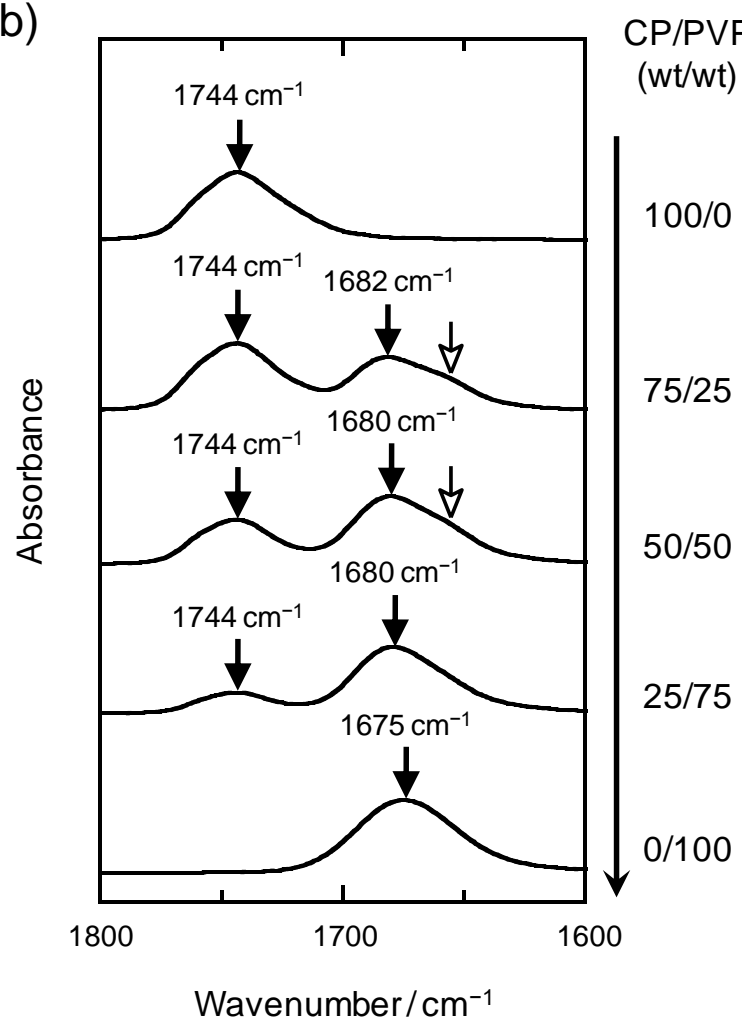

599

Fig. 3 FT-IR spectra of $\mathrm{CP}_{1.71}$, PVP, and their blends in the frequency regions of (a) $\mathrm{O}-\mathrm{H}$ and (b) $\mathrm{C}=\mathrm{O}$ stretching vibrations. Solid arrows indicate a peak-top position in the respective specific absorption bands, and white arrows indicate a shoulder band associated with hydrogen bonding (see text for discussion). 


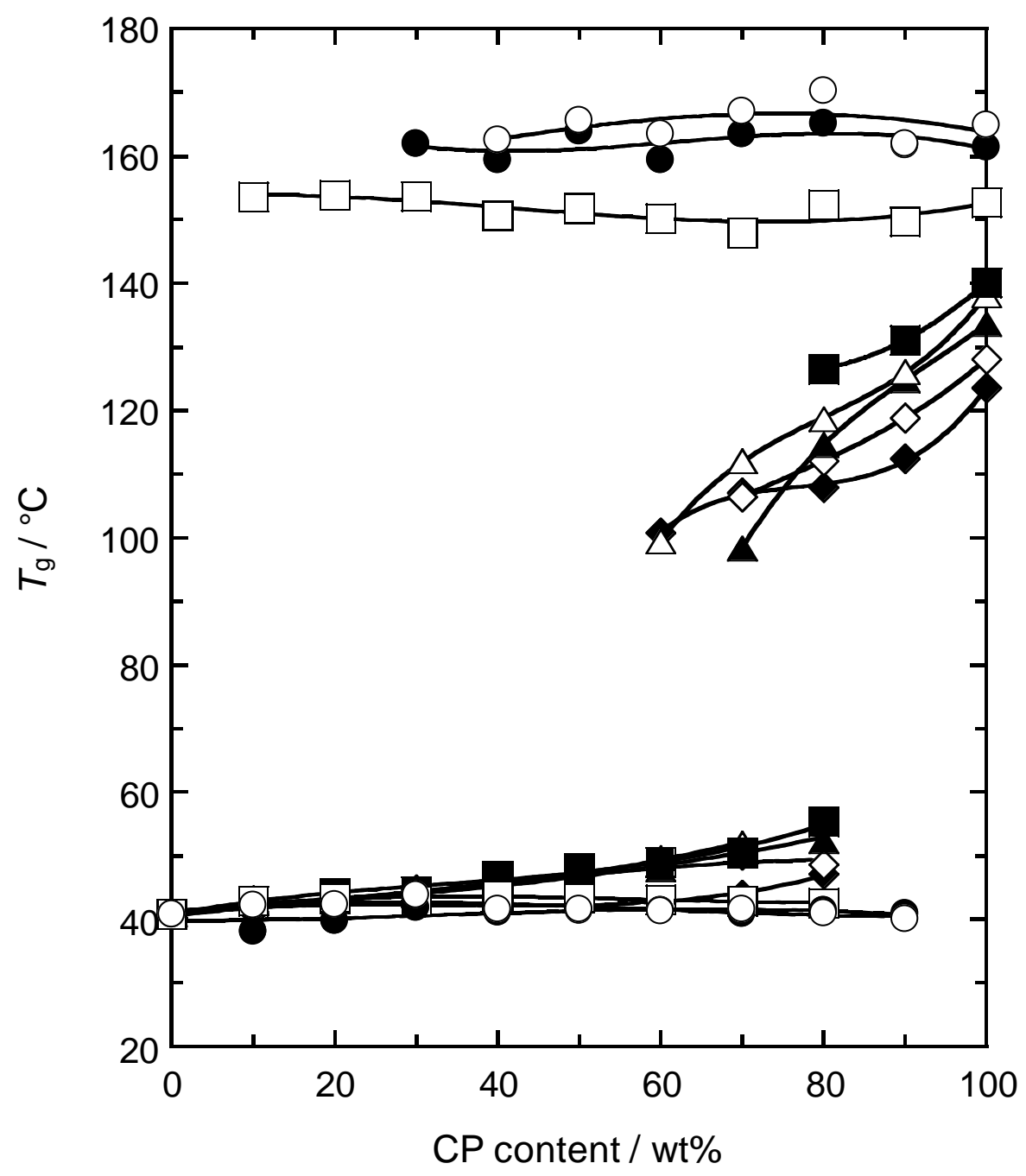

605

606

607 Fig. $4 T_{\mathrm{g}}$ versus composition plots for eight series of CP/PVAc blends. DS of CP: $\bigcirc, 1.90$;

608

, 2.18; $\square, 2.35 ; \square, 2.54 ; \triangle, 2.62 ;$

$\boldsymbol{\Delta}, 2.72 ; \diamond, 2.81 ; \diamond, 2.93$

609 


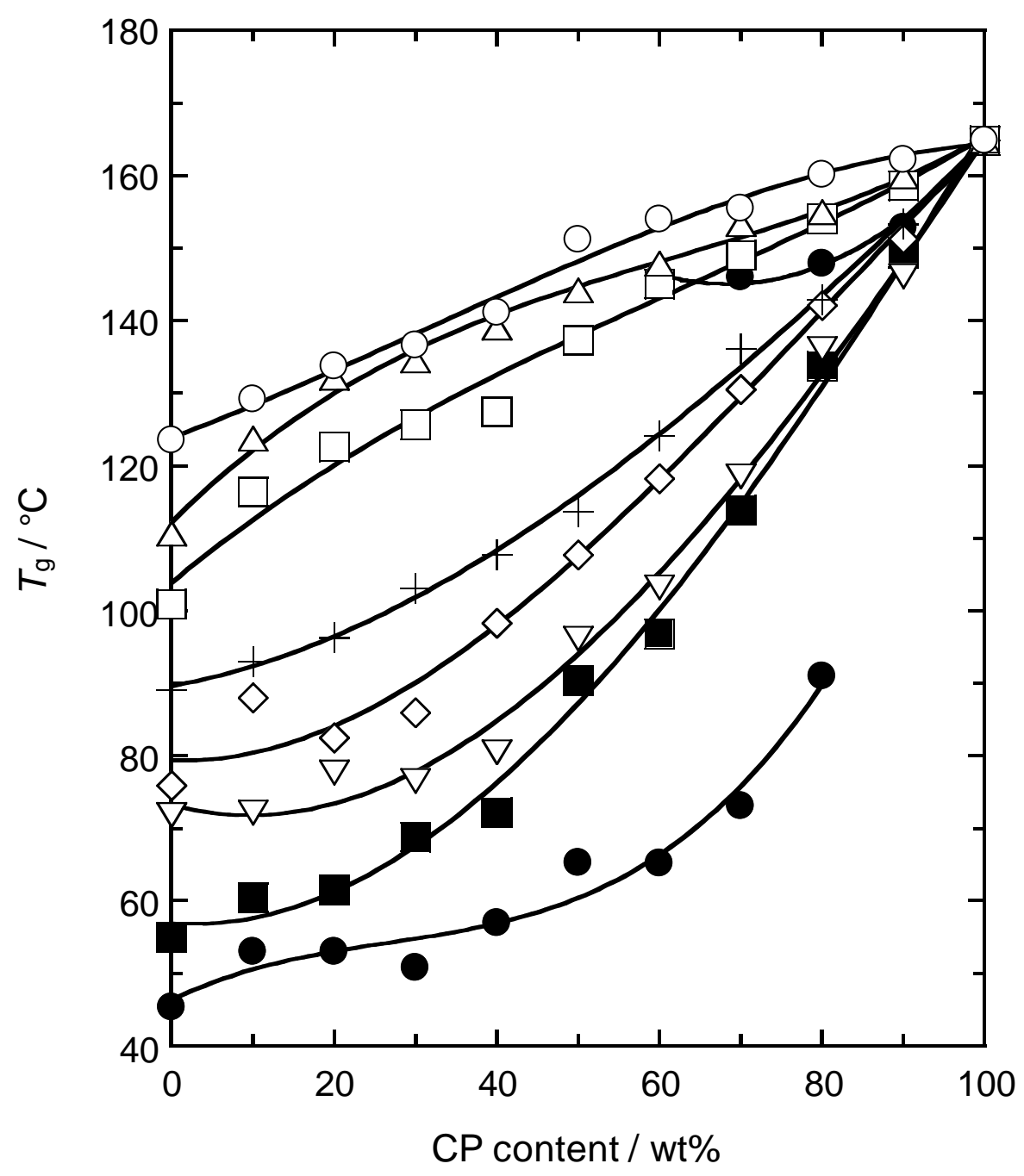

610

611

612 Fig. 5 Composition dependence of $T_{\mathrm{g}}$ for eight series of $\mathrm{CP}_{1.90} / \mathrm{P}(\mathrm{VP}-$ co-VAc) blends.

$613 \quad$ VP:VAc in P(VP-co-VAc): $\bullet, 10: 90 ; \mathbf{\square}, 23: 77 ; \nabla, 33: 67 ; \diamond, 40: 60 ;+, 52: 48 ; \square, 62: 38 ; \triangle$, $614 \quad 73: 27 ; \bigcirc, 87: 13$ 
615

(a)

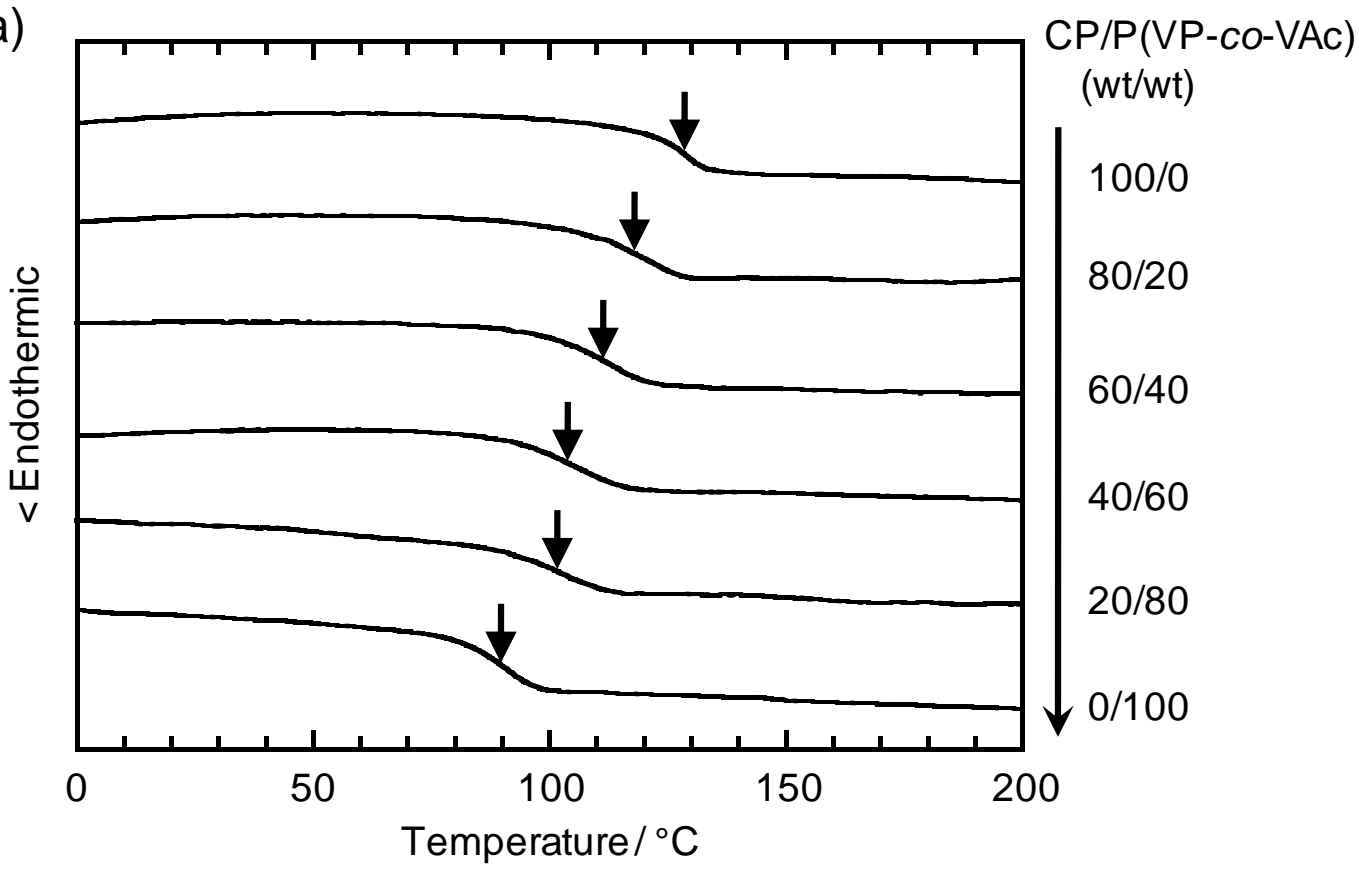

(b)

616

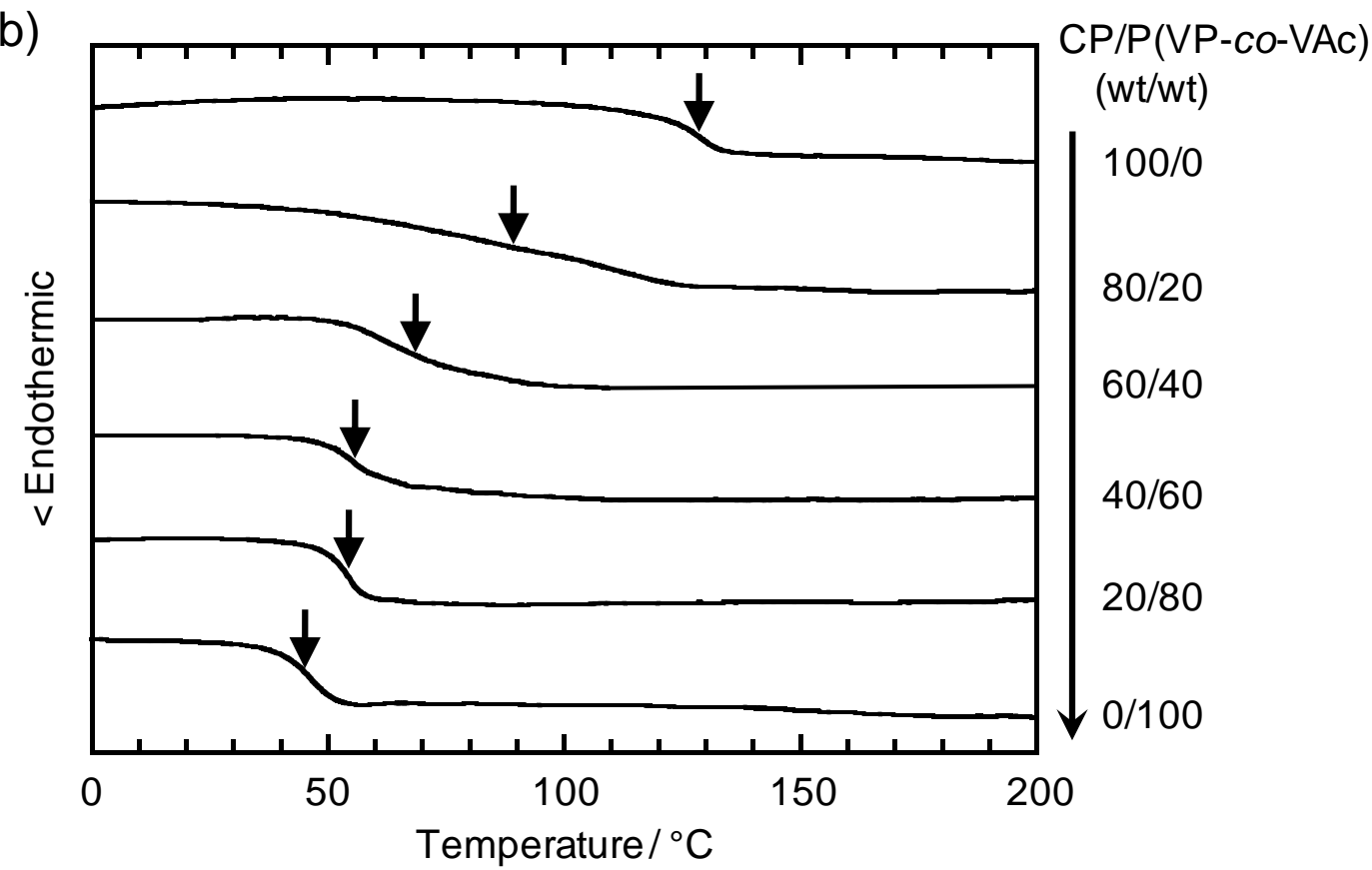

617

618 Fig. 6 DSC thermograms obtained for (a) $\mathrm{CP}_{2.89} / \mathrm{P}\left(\mathrm{VP}_{0.52}-\mathrm{co}-\mathrm{VAc}_{0.48}\right)$ and (b)

$619 \mathrm{CP}_{2.89} / \mathrm{P}\left(\mathrm{VP}_{0.10^{-}}-\mathrm{V}^{-} \mathrm{VAc}_{0.90}\right)$ blends. Arrows indicate a $T_{\mathrm{g}}$ position.

620 
621

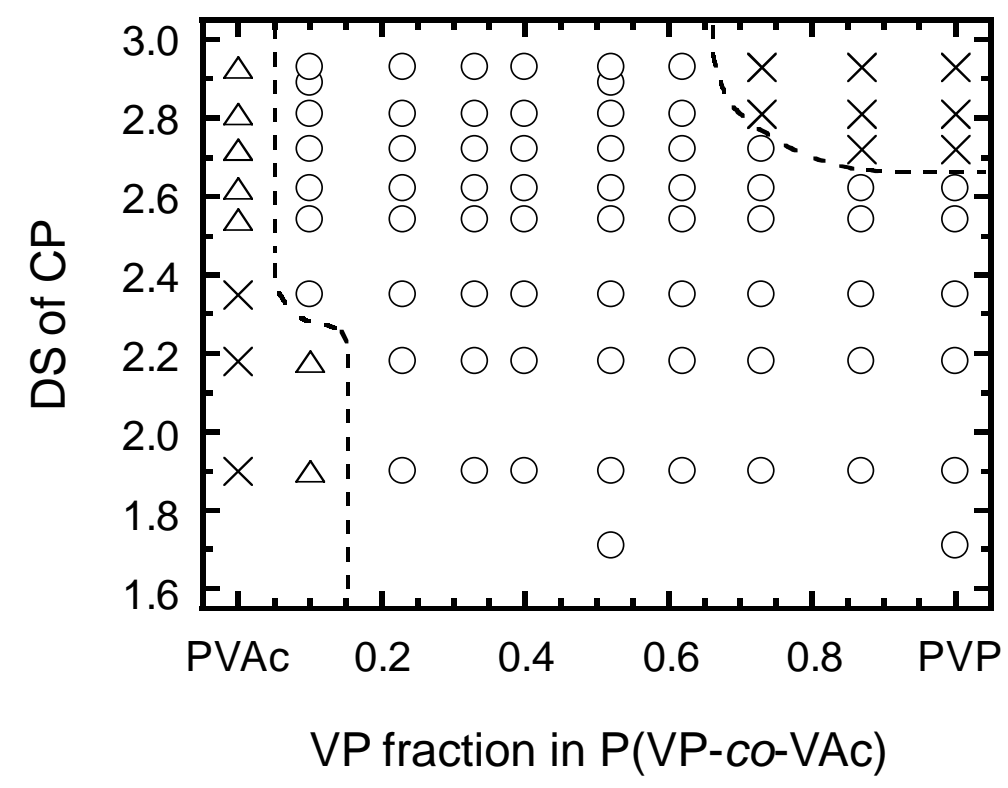

622

623 Fig. 7 Miscibility map for CP/P(VP-co-VAc) blends, as a function of DS of CP and VP 624 fraction in $\mathrm{P}(\mathrm{VP}-\mathrm{co}-\mathrm{VAc})$. Symbols indicate that a given pair of $\mathrm{CP} / \mathrm{P}(\mathrm{VP}-\mathrm{co}-\mathrm{VAc})$ is 625 miscible $(\bigcirc)$, immiscible $(\times)$, or partially miscible $(\triangle)$.

626 
(a)

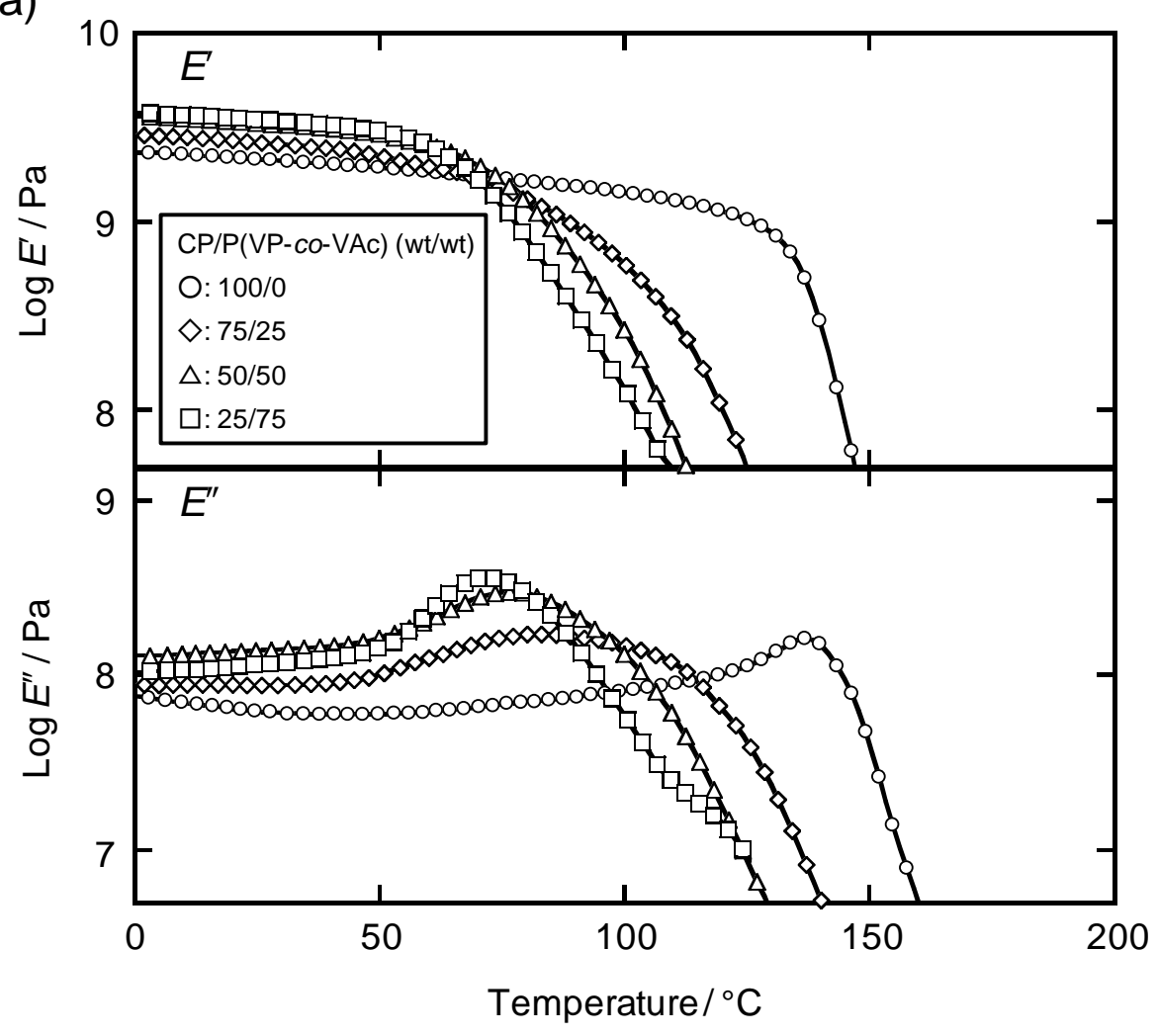

(b)

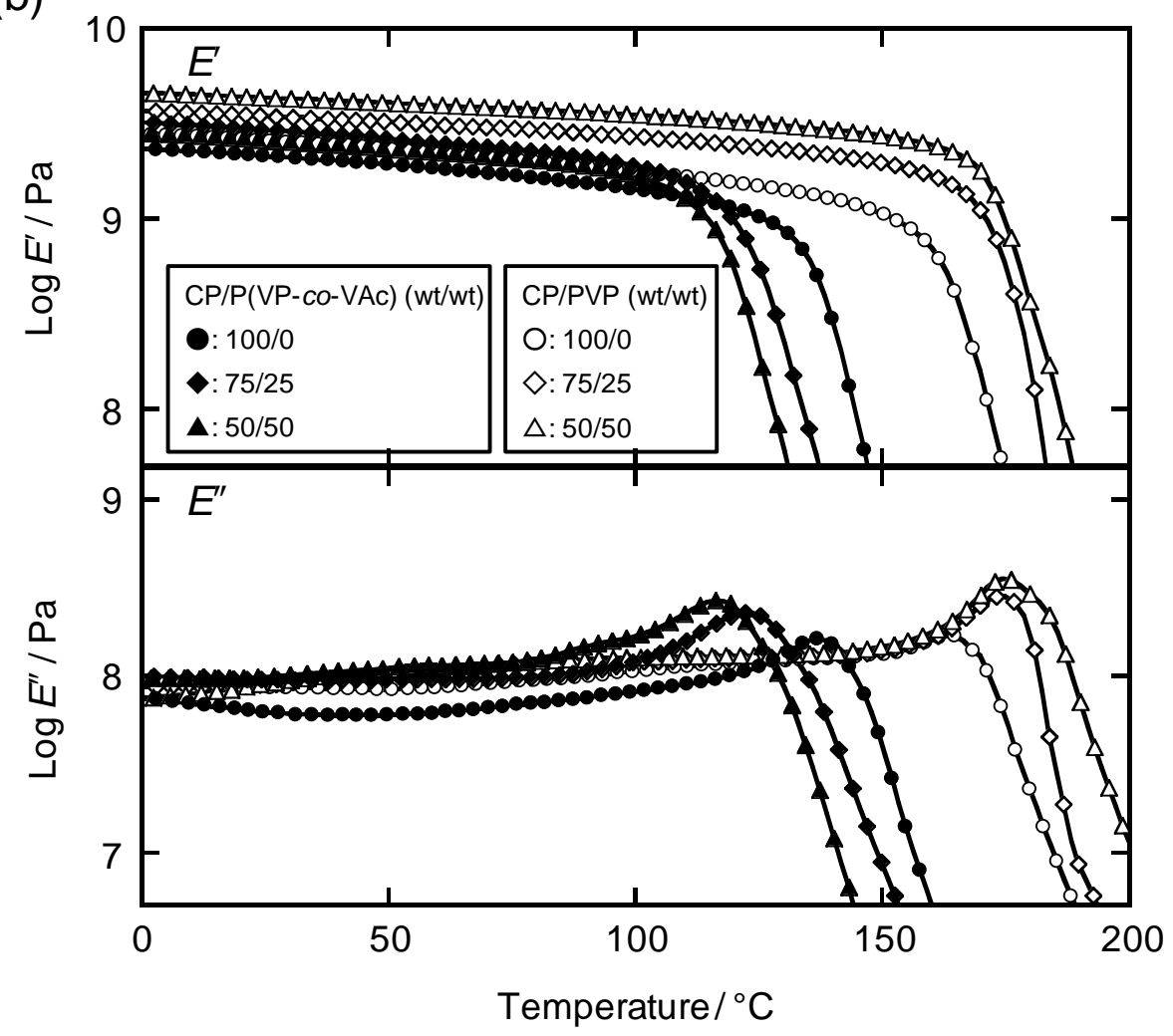

Fig. 8 Temperature dependence of the dynamic storage modulus $E^{\prime}$ and loss modulus $E^{\prime \prime}$ for

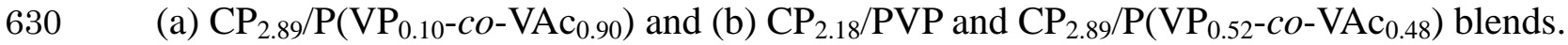




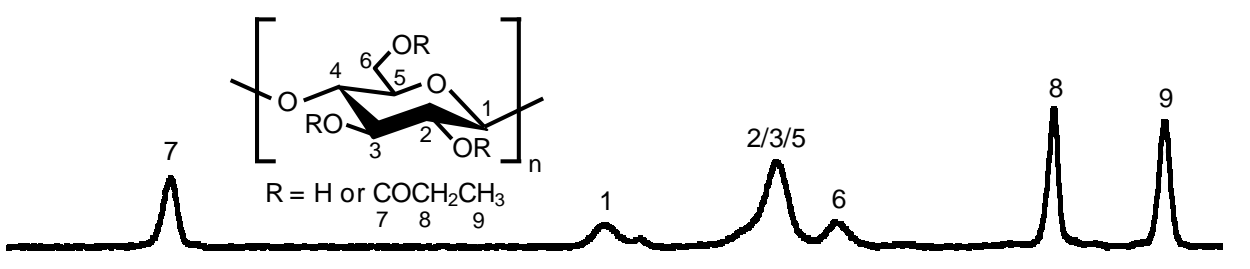

CP/P(VP-co-VAc)

$(w t / w t)$

$100 / 0$

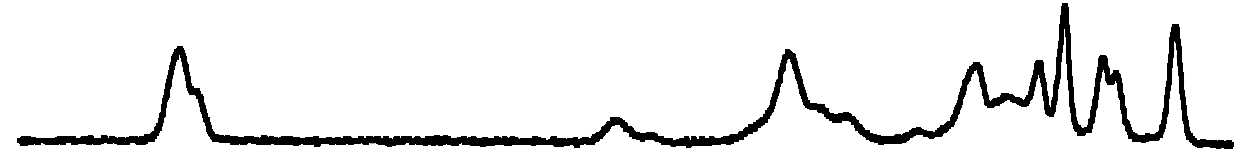

$50 / 50$

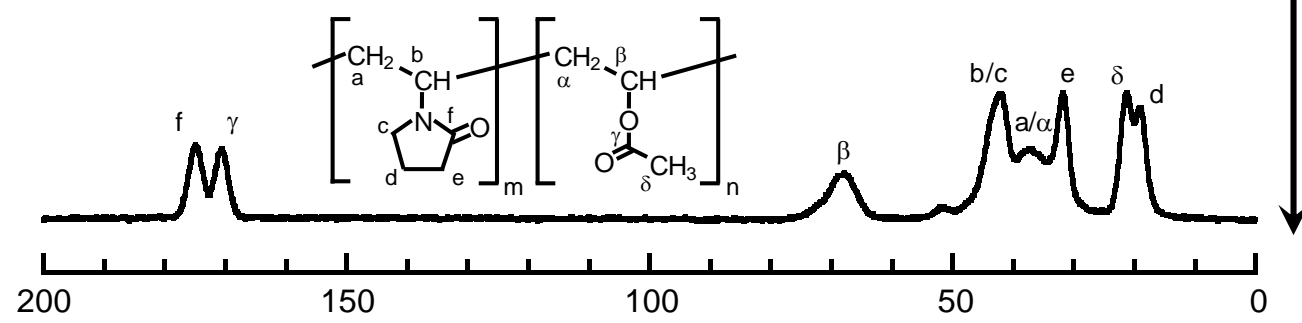

$0 / 100$

631

Chemical shift/ppm

632

633 Fig. 9 Solid-state ${ }^{13} \mathrm{C}$ CP/MAS NMR spectra for $\mathrm{CP}_{2.89}, \mathrm{P}\left(\mathrm{VP}_{0.52}-\mathrm{co}-\mathrm{VAc}_{0.48}\right)$, and their $63450 / 50$ blend.

635 
636

(a)

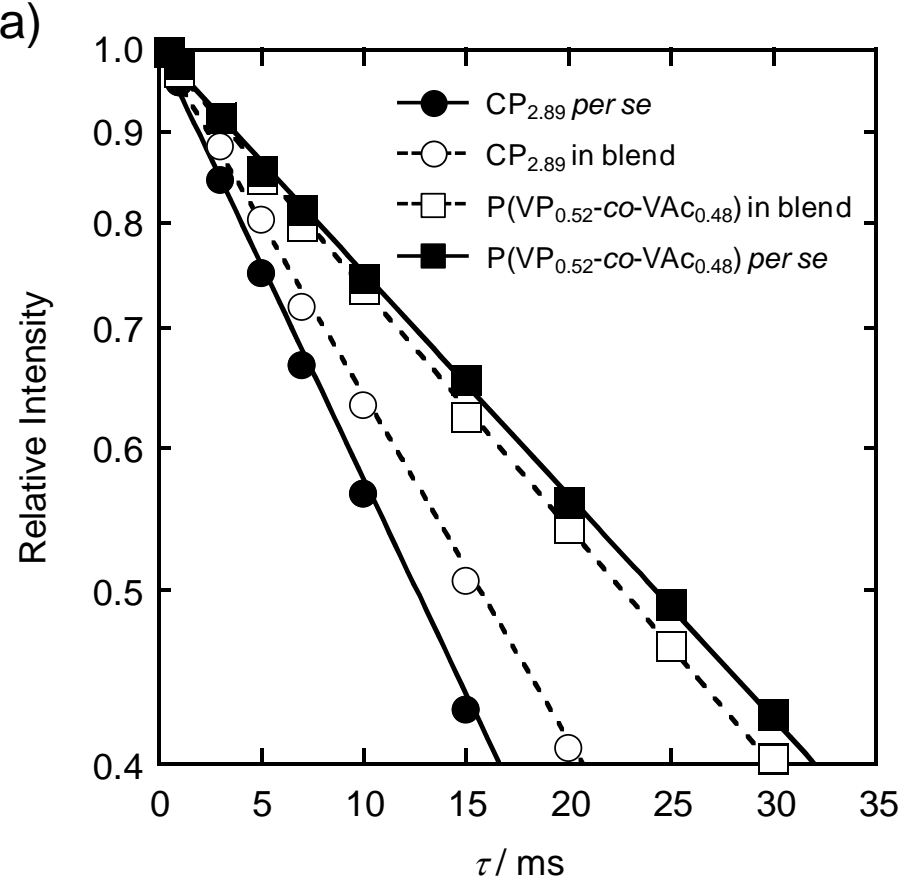

(b)

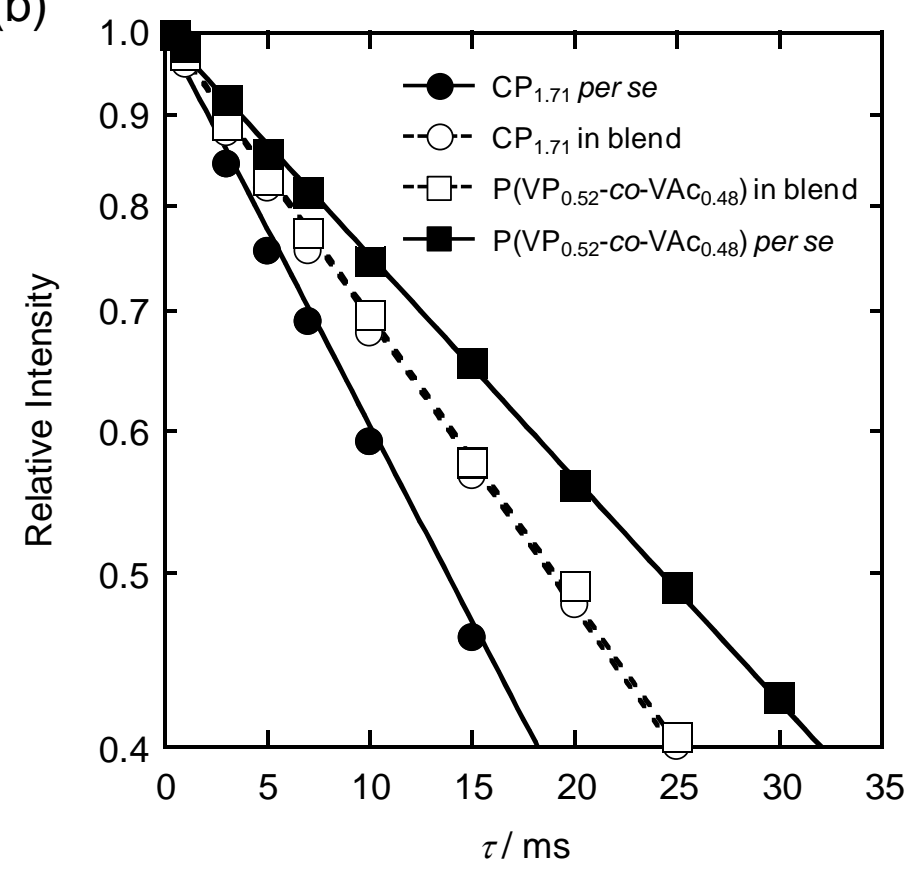

639 Fig. 10 Semilogarithmic plots of the decay of ${ }^{13} \mathrm{C}$ resonance intensities as a function of 640 spin-locking time $\tau$, for solid films of (a) $\mathrm{CP}_{2.89}, \mathrm{P}\left(\mathrm{VP}_{0.52}-c o-\mathrm{VAc}_{0.48}\right)$, and their 50/50 blend, 641 and (b) $\mathrm{CP}_{1.71}, \mathrm{P}\left(\mathrm{VP}_{0.52}-\mathrm{co}-\mathrm{VAc}_{0.48}\right)$, and their 50/50 blend. The monitoring was conducted 642 for the peak intensity of $\mathrm{C} 2 / \mathrm{C} 3 / \mathrm{C} 5$ pyranose carbons of $\mathrm{CP}$ and that of $\mathrm{C}_{\mathrm{b}} / \mathrm{C}_{\mathrm{c}}$ carbons of the 643 copolymer (see Fig. 9). 